Atmos. Chem. Phys., 17, 12797-12812, 2017

https://doi.org/10.5194/acp-17-12797-2017

(c) Author(s) 2017. This work is distributed under

the Creative Commons Attribution 3.0 License.

\title{
Hygroscopic behavior and chemical composition evolution of internally mixed aerosols composed of oxalic acid and ammonium sulfate
}

\author{
Xiaowei Wang ${ }^{1,2}$, Bo Jing ${ }^{3}$, Fang Tan $^{3,4}$, Jiabi Ma ${ }^{1}$, Yunhong Zhang ${ }^{1}$, and Maofa Ge ${ }^{3,4,5}$ \\ ${ }^{1}$ The Institute of Chemical Physics, School of Chemistry and Chemical Engineering, Beijing Institute of Technology, \\ Beijing 100081, China \\ ${ }^{2}$ School of Chemical Engineering and Pharmaceutics, Henan University of Science and Technology, Luoyang 471023, China \\ ${ }^{3}$ Beijing National Laboratory for Molecular Sciences (BNLMS), State Key Laboratory for Structural Chemistry of Unstable \\ and Stable Species, CAS Research/Education Center for Excellence in Molecular Sciences, Institute of Chemistry, Chinese \\ Academy of Sciences, Beijing 100190, China \\ ${ }^{4}$ University of Chinese Academy of Sciences, Beijing 100049, China \\ ${ }^{5}$ Center for Excellence in Regional Atmospheric Environment, Institute of Urban Environment, Chinese Academy of \\ Sciences, Xiamen 361021, China
}

Correspondence to: Yunhong Zhang (yhz@bit.edu.cn) and Maofa Ge (gemaofa@iccas.ac.cn)

Received: 13 May 2017 - Discussion started: 29 May 2017

Revised: 4 September 2017 - Accepted: 26 September 2017 - Published: 27 October 2017

\begin{abstract}
Although water uptake of aerosol particles plays an important role in the atmospheric environment, the effects of interactions between components on chemical composition and hygroscopicity of particles are still not well constrained. The hygroscopic properties and phase transformation of oxalic acid (OA) and mixed particles composed of ammonium sulfate (AS) and OA with different organic to inorganic molar ratios (OIRs) have been investigated by using confocal Raman spectroscopy. It is found that OA droplets first crystallize to form OA dihydrate at $71 \%$ relative humidity $(\mathrm{RH})$, and further lose crystalline water to convert into anhydrous $\mathrm{OA}$ around $5 \% \mathrm{RH}$ during the dehydration process. The deliquescence and efflorescence point for AS is determined to be $80.1 \pm 1.5 \% \mathrm{RH}$ and $44.3 \pm 2.5 \% \mathrm{RH}$, respectively. The observed efflorescence relative humidity (ERH) for mixed OA / AS droplets with OIRs of $1: 3,1: 1$ and $3: 1$ is $34.4 \pm 2.0,44.3 \pm 2.5$ and $64.4 \pm 3.0 \% \mathrm{RH}$, respectively, indicating the elevated OA content appears to favor the crystallization of mixed systems at higher RH. However, the deliquescence relative humidity (DRH) of AS in mixed OA / AS particles with OIRs of $1: 3$ and $1: 1$ is observed to occur at $81.1 \pm 1.5$ and $77 \pm 1.0 \% \mathrm{RH}$, respectively. The Raman spectra of mixed OA / AS droplets indicate the formation of ammonium hydrogen oxalate $\left(\mathrm{NH}_{4} \mathrm{HC}_{2} \mathrm{O}_{4}\right)$ and
\end{abstract}

ammonium hydrogen sulfate $\left(\mathrm{NH}_{4} \mathrm{HSO}_{4}\right)$ from interactions between OA and AS in aerosols during the dehydration process on the time scale of hours, which considerably influence the subsequent deliquescence behavior of internally mixed particles with different OIRs. The mixed OA / AS particles with an OIR of $3: 1$ exhibit no deliquescence transition over the $\mathrm{RH}$ range studied due to the considerable transformation of $\left(\mathrm{NH}_{4}\right)_{2} \mathrm{SO}_{4}$ into $\mathrm{NH}_{4} \mathrm{HC}_{2} \mathrm{O}_{4}$ with a high DRH. Although the hygroscopic growth of mixed OA / AS droplets is comparable to that of AS or OA at high RH during the dehydration process, Raman growth factors of mixed particles after deliquescence are substantially lower than those of mixed OA / AS droplets during the efflorescence process and further decrease with elevated OA content. The discrepancies for Raman growth factors of mixed OA / AS particles between the dehydration and hydration process at high $\mathrm{RH}$ can be attributed to the significant formation of $\mathrm{NH}_{4} \mathrm{HC}_{2} \mathrm{O}_{4}$ and residual $\mathrm{OA}$, which remain solid at high $\mathrm{RH}$ and thus result in less water uptake of mixed particles. These findings improve the understanding of the role of reactions between dicarboxylic acid and inorganic salt in the chemical and physical properties of aerosol particles, and might have important implications for atmospheric chemistry. 


\section{Introduction}

Atmospheric aerosols have vital impacts on the Earth's climate directly by scattering, reflecting and absorbing solar radiation, and indirectly by influencing formation of clouds and precipitation (Tang and Munkelwitz, 1994b; Jacobson et al., 2000; Penner et al., 2001; Pöschl, 2005; Von Schneidemesser et al., 2015). Direct and indirect effects depend on the chemical and physical properties of atmospheric aerosols, including size, structure, hygroscopicity and chemical composition. Field observations indicate that aerosol particles are generally internal mixtures of inorganic and organic compounds in the atmosphere (Saxena et al., 1995; Murphy et al., 1998, 2006; Pratt and Prather, 2010). Ammonium sulfate (AS) is one of the most abundant inorganic constituents in the atmosphere, the hygroscopicity of which has been widely investigated (Liu et al., 2008; Cziczo et al., 1997; Laskina et al., 2015).

Oxalic acid (OA) is ubiquitous and has been identified as the dominant dicarboxylic acid in urban and remote atmospheric aerosols (Chebbi and Carlier, 1996; Kanakidou et al., 2004; Yang and Yu, 2008; Wang et al., 2012; Kawamura and Bikkina, 2016). Previous studies have focused on deliquescence behavior of pure OA (Peng et al., 2001; Braban et al., 2003; Miñambres et al., 2013; Ma et al., 2013a; Jing et al., 2016). It was found that due to its high deliquescence point, OA exhibited no deliquescence transition or hygroscopic growth within the relative humidity $(\mathrm{RH})$ range studied by an electrodynamic balance (EDB) (Peng et al., 2001), vapor sorption analyzer (Ma et al., 2013a) or hygroscopicity tandem differential mobility analyzer (HTDMA) (Jing et al., 2016). Braban et al. (2003) reported that OA could deliquesce at $98 \%$ RH using aerosol flow tube Fourier transform infrared spectroscopy (AFT-FTIR). However, the study on the efflorescence behavior of OA during the dehydration process remains limited (Peng et al., 2001; Mikhailov et al., 2009). Peng et al. (2001) observed the efflorescence transition of OA using EDB while Mikhailov et al. (2009) reported continuous hygroscopic growth of OA during both hydration and dehydration processes using the HTDMA.

The dicarboxylic acids can affect properties of internally mixed aerosol particles such as hygroscopicity, phase transition, solubility and chemical reactivity (Lightstone et al., 2000; Brooks et al., 2002; Sjogren et al., 2007; Pradeep Kumar et al., 2003; Treuel et al., 2011; Laskin et al., 2012; Drozd et al., 2014; Peng et al., 2016; Jing et al., 2016, 2017; Li et al., 2017). Field measurements have observed the formation of low-volatility organic salts in atmospheric particles due to the reactions of organic acids with mineral salts, chloride salts, nitrate salts, ammonium and amines (Sullivan and Prather, 2007; Laskin et al., 2012; Wang and Laskin, 2014; Smith et al., 2010). The organic salts formed typically have varying hygroscopicity compared to the corresponding organic acids. Thus, these drastic changes in aerosol composition have potential effects on the water uptake and related physicochemical properties of particles. The effects of OA on deliquescence behaviors of AS have been extensively investigated (Brooks et al., 2002; Prenni et al., 2003; Wise et al., 2003; Miñambres et al., 2013; Jing et al., 2016). The majority of studies found that the presence of OA had no obvious effect on the deliquescence process of OA / AS mixtures with minor OA content (Brooks et al., 2002; Prenni et al., 2003; Wise et al., 2003). To our knowledge, there is still a lack of studies on the efflorescence process of OA / AS mixed systems. In fact, the efflorescence behavior is a critical hygroscopic characteristic of atmospheric aerosols, which may favor specific chemical interactions between components within the supersaturated droplets. For example, previous studies have found that chloride depletion could occur in the $\mathrm{NaCl} /$ dicarboxylic acid mixed aerosols during the dehydration or efflorescence process, which led to the formation of organic salts and in turn affected subsequent deliquescence behaviors of aerosols (Laskin et al., 2012; Ghorai et al., 2014). OA has been found to react with both monoand divalent cations to form low-volatility and low solubility compounds (Drozd et al., 2014). Miñambres et al. (2013) proposed that OA might react with AS to form ammonium hydrogen oxalate and ammonium hydrogen sulfate within OA / AS solution. Due to the lack of available thermodynamic data, the aerosol thermodynamic models typically assume that upon dehydration dicarboxylic acid could only form an organic solid without the organic salt in the inorganic electrolyte / dicarboxylic acid system (Clegg and Seinfeld, 2006; Amundson et al., 2007). Thus, the incorporation of organic salts formed from interactions between inorganic salts and organic acids is crucial to the modeling of hygroscopic properties of mixed organic / inorganic particles. It merits further investigation on the interactions between OA and AS and the related influence on the water uptake behaviors of aerosols during the dehydration and hydration processes.

Raman spectroscopy is a powerful technique to characterize aerosol compositions, water contents, molecular interactions and particle phases especially for the efflorescence process (Ma and He, 2012; Laskina et al., 2013; Zhou et al., 2014; Wang et al., 2015). In this study, the phase transformations and hygroscopic properties of OA and mixed OA / AS droplets with varying OA content were studied by confocal Raman spectroscopy in conjunction with optical microscopy. Furthermore, we explored the effects of reactions between $\mathrm{OA}$ and $\mathrm{AS}$ on the chemical compositions and hygroscopic properties of mixed OA / AS droplets.

\section{Experimental section}

\subsection{Sample preparation}

AS and OA dihydrate were purchased from Sinopharm Chemical Reagent Co. Ltd. (99.0\% purity) and used with- 
out further purification. The $0.5 \mathrm{molL}^{-1}$ pure component AS and OA solutions were prepared by dissolving AS and OA dihydrate in ultrapure water $(18.2 \mathrm{M} \Omega \mathrm{cm}$, Barnstead Easypure II), respectively. The mixed OA / AS solutions with different organic to inorganic molar ratios (OIRs) of $1: 3,1: 1$ and $3: 1$ were obtained by dissolving a designated amount of OA into AS solutions. The sample solution was discharged from a syringe. Then, residual solution in the syringe was pushed rapidly to generate aerosol droplets spraying onto a polytetrafluoroethylene (PTFE) substrate fixed to the bottom of the sample cell. Then, the sample cell was promptly sealed by a transparent polyethylene film. The RH in the sample cell was regulated by nitrogen streams consisting of a mixture of water-saturated $\mathrm{N}_{2}$ and dry $\mathrm{N}_{2}$ at controlled flow rates. At $\sim 95 \% \mathrm{RH}$, the droplets with a diameter of 30-40 $\mu \mathrm{m}$ detected by an optical microscope $(50 \times$ objective, 0.75 numerical aperture) were selected to acquire the Raman spectra. The dry size of these particles after efflorescence ranged from 10 to $20 \mu \mathrm{m}$. The RH and temperature of the outflow from the sample cell was measured by a humidity/temperature meter (Centertek Center 313) with an accuracy of $\pm 2.5 \%$ below $90 \% \mathrm{RH}$ and $\pm 0.7 \mathrm{~K}$ placed near the exit of the sample cell. The temperature accuracy of $0.7 \mathrm{~K}$ could result in an uncertainty of $4 \%$ at a RH of $95 \%$. The temperature of the sample was maintained at $297 \pm 0.5 \mathrm{~K}$ by using an automatic thermostat.

\subsection{Apparatus and conditions for the measurements}

The experimental setup used in this study was described in detail in a previous work (Wang et al., 2008; Dong et al., 2009; Zhou et al., 2014). Briefly, the Renishaw InVia confocal Raman spectrometer equipped with a Leica DMLM microscope was used to acquire the Raman spectra. An argonion laser (wavelength $514.5 \mathrm{~nm}$, model Stellar-REN, ModuLaser) was used as an excitation source with an output power of $20 \mathrm{~mW}$, and a $514.5 \mathrm{~nm}$ notch filter was adopted to remove the strong Rayleigh scattering. A $1800 \mathrm{~g} \mathrm{~mm}^{-1}$ (grooves per millimeter) grating was used to obtain the spectra in the range of $200-4000 \mathrm{~cm}^{-1}$ with a resolution of about $1 \mathrm{~cm}^{-1}$. Spectral calibration was made using the $520 \pm 0.05 \mathrm{~cm}^{-1}$ Stokes shift of the silicon band before performing measurements. Then, spectroscopic measurements were made on droplets observed by using the Leica DMLM microscope with a $50 \times$ objective lens (0.75 numerical aperture). The spectra were obtained with three spectral scans, and each time with an accumulation time of $10 \mathrm{~s}$. The sample droplets were injected onto the substrate at high $\mathrm{RH}(\sim 95 \% \mathrm{RH})$. Subsequently, the RH was decreased stepwise for a slow dehydration process, and then increased stepwise from $\mathrm{RH}<3 \%$ to high $\mathrm{RH}$ for a hydration process. The decrease rate was typically 5$6 \% \mathrm{RH}$ every $40 \mathrm{~min}$ and the rate remained $2-3 \mathrm{RH}$ every 40 min near the phase transition. The RH was decreased continuously in a few minutes for a rapid dehydration process. The particles were equilibrated with water vapor at a given (a) Dehydration, ammonium sulfate

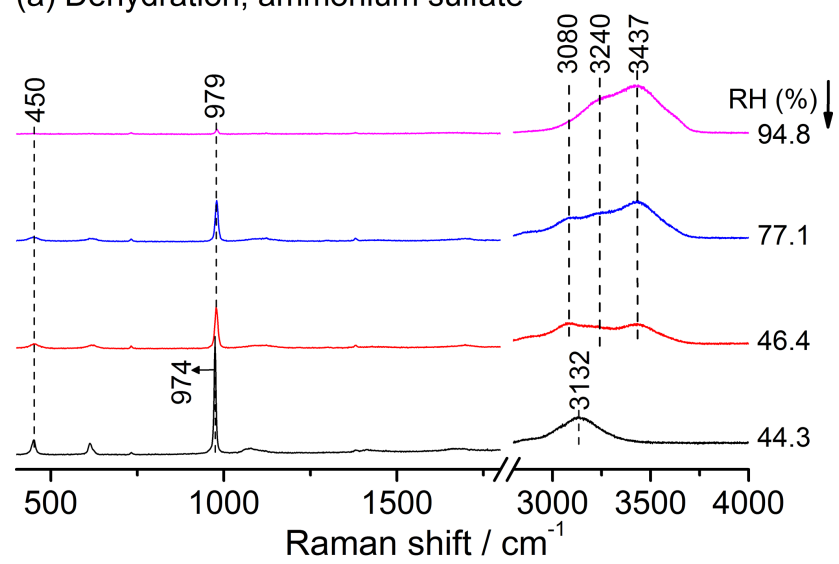

(b) Hydration, ammonium sulfate

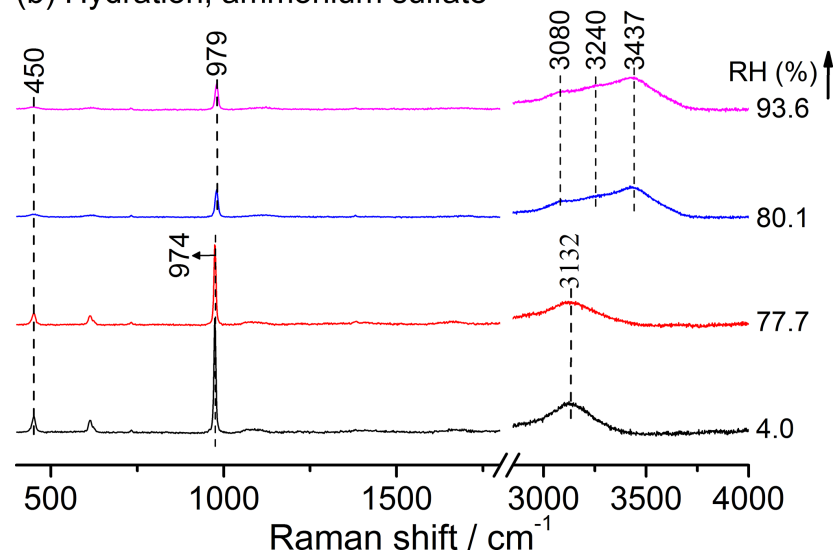

Figure 1. Raman spectra of ammonium sulfate (AS) droplets at various RH values during the (a) dehydration process and (b) hydration process.

RH for about $40 \mathrm{~min}$, during which the intensity ratio of the water peak $\left(3430 \mathrm{~cm}^{-1}\right)$ to the sulfate peak $\left(980 \mathrm{~cm}^{-1}\right)$ remained constant. The spectra of AS, OA and mixed OA / AS droplets were monitored and measured through a full humidity cycle. Multiple particles (three or four) were selected to acquire the Raman spectra through each humidity cycle. Each humidity cycle experiment was repeated at least three times. All the measurements were taken at ambient temperature of about $297 \mathrm{~K}$.

Raman growth factor, $g(\mathrm{RH})$, is defined as the ratio of the integrated area of the $\mathrm{OH}$ stretching mode of water (3350$\left.3700 \mathrm{~cm}^{-1}\right)$ at each RH $\left(A_{\mathrm{RH}}\right)$ normalized to that of a dry particle $\left(A_{\mathrm{RH} 0}\right)$ according to Eq. (1) (Laskina et al., 2015).

$g(\mathrm{RH})=A_{\mathrm{RH}} / A_{\mathrm{RH} 0}$,

where $A_{\mathrm{RH}}$ is the integrated area of the $\mathrm{OH}$ stretching mode from water $\left(3350-3700 \mathrm{~cm}^{-1}\right)$ at a specific RH and $A_{\mathrm{RH} 0}$ is that of a dry particle. Hygroscopic growth curves are acquired by plotting the average Raman growth factor of duplicate particles as a function of RH. 
Table 1. Molecular vibration assignments of pure OA and AS droplets.

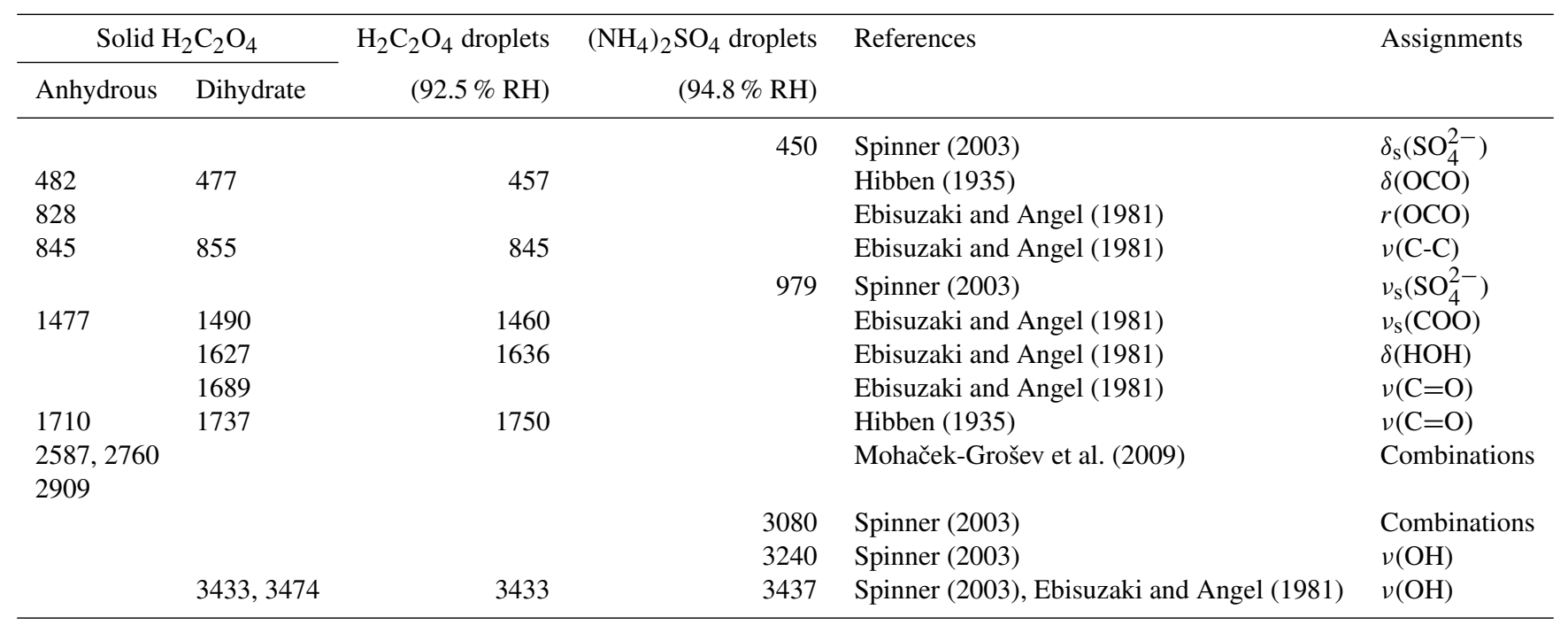

$v$ : stretching, $\delta$ : bending, $r$ : rocking and s: symmetric mode.

\section{Results and discussion}

\subsection{Raman spectra of pure AS and OA droplets}

The Raman spectra of AS droplets during the dehydration and hydration processes can be found in Fig. 1a and b, respectively. AS droplets effloresce at $44.3 \pm 2.5 \% \mathrm{RH}$, as indicated by the disappearance of the water peak centered at $3437 \mathrm{~cm}^{-1}$ and a red-shift in the $v_{\mathrm{s}}\left(\mathrm{SO}_{4}^{2-}\right)$ peak position from 979 to $974 \mathrm{~cm}^{-1}$ during the dehydration process. For the hydration process, the deliquescence of AS particles is observed to occur at $80.1 \pm 1.5 \% \mathrm{RH}$, resulting in an abrupt increase in the absorbance of the water peak centered at $3437 \mathrm{~cm}^{-1}$ and a blue-shift in the $v_{\mathrm{s}}\left(\mathrm{SO}_{4}^{2-}\right)$ peak position from 974 to $979 \mathrm{~cm}^{-1}$.

The Raman spectra of OA droplets with varying RH during the dehydration and hydration processes are shown in Fig. 2, and the assignments of the peaks for OA are presented in Table 1 according to previous studies (Hibben, 1935; Ebisuzaki and Angel, 1981; Mohaček-Grošev et al., 2009). As seen in Fig. 2a, the feature bands for OA droplets are observed at 1460,1750 and $3433 \mathrm{~cm}^{-1}$ at $92.5 \% \mathrm{RH}$. At lower RH around $71 \%$ (Fig. 2a; magenta line), these bands shift to $1490,1737,3433$ and $3474 \mathrm{~cm}^{-1}$, and a new band at $1689 \mathrm{~cm}^{-1}$ occurs, which is entirely consistent with the spectrum of OA dihydrate (Fig. 2a; black dashed line). It indicates that OA droplets crystallize to form OA dihydrate. OA particles after efflorescence exist in the form of dihydrate until $6.6 \% \mathrm{RH}$, at which the Raman spectrum of dihydrate remains unchanged for $40 \mathrm{~min}$. Once RH decreases to $\sim 5.0 \%$, the peaks promptly shift to $1477,1710,2587,2760$ and $2909 \mathrm{~cm}^{-1}$, and peaks at 3433 and $3474 \mathrm{~cm}^{-1}$ assigned to $v(\mathrm{OH})$ vanish, which is the spectral feature of anhydrous
OA. This result implies that OA dihydrate is converted to anhydrous $\mathrm{OA}$ in the RH range around $5.0 \%$. The Raman spectra of anhydrous OA particles during the hydration process as a function of RH are shown in Fig. 2b. It can be found that the Raman spectra feature for anhydrous OA particles occurs at $\mathrm{RH}<19.6 \%$. At $19.6 \% \mathrm{RH}$, the peaks observed at 1490 , 1737,3433 and $3474 \mathrm{~cm}^{-1}$ are identical to that of OA dihydrate (Fig. 2a; black dashed line), indicating the formation of OA dihydrate. The observation of no spectral change until $94 \% \mathrm{RH}$ suggests that OA dihydrate shows no deliquescence transition in the 0-94\% RH range studied, consistent with previous studies (Peng et al., 2001; Braban et al., 2003; Ma et al., 2013a; Jing et al., 2016). The transition point of anhydrous OA to OA dihydrate upon hydration is $17.9-19.6 \%$ (Fig. 2b), in agreement with the results reported by Braban et al. (2003) and Ma et al. (2013a).

\subsection{Raman spectra of OA / AS mixtures}

The Raman spectra of mixed OA / AS droplets with OIRs of $1: 3,1: 1$ and $3: 1$ at various RHs during the dehydration and hydration processes are depicted in Figs. 3 and 4 , respectively. Since spectral features upon hydration are identical to the dehydration process, here we only analyzed spectral evolution of the efflorescence process in detail. The detailed assignments are summarized in Table 2. For the mixed OA / AS droplets (OIR $=1: 3$ ) at $96.2 \% \mathrm{RH}$ (seen in Fig. 3a), the bands at 979 and $1049 \mathrm{~cm}^{-1}$ are characteristic peaks of aqueous $\mathrm{SO}_{4}^{2-}$ and $\mathrm{HSO}_{4}^{-}\left(v_{\mathrm{s}}\left(\mathrm{SO}_{3}\right)\right)$, respectively. In addition, the peak at 1741 and $1446 \mathrm{~cm}^{-1}$ can be assigned to the vibrating mode of aqueous $\mathrm{OA}$ and $\mathrm{HC}_{2} \mathrm{O}_{4}^{-}$, respectively. With decreasing RH, only small changes are observed in the spectra until the RH reaches $34.4 \%$. At $34.4 \% \mathrm{RH}$, the shift of the $v_{\mathrm{s}}\left(\mathrm{SO}_{4}^{2-}\right)$ peak from 979 to $974 \mathrm{~cm}^{-1}$ indi- 
Table 2. Molecular vibration assignments of mixed OA / AS systems.

\begin{tabular}{rrrll}
\hline $\begin{array}{r}\mathrm{H}_{2} \mathrm{C}_{2} \mathrm{O}_{4}-\left(\mathrm{NH}_{4}\right)_{2} \mathrm{SO}_{4} \\
(1: 3), \mathrm{RH}=96.2 \%\end{array}$ & $\begin{array}{r}\mathrm{H}_{2} \mathrm{C}_{2} \mathrm{O}_{4}-\left(\mathrm{NH}_{4}\right)_{2} \mathrm{SO}_{4} \\
(1: 1), \mathrm{RH}=96.1 \%\end{array}$ & $\begin{array}{r}\mathrm{H}_{2} \mathrm{C}_{2} \mathrm{O}_{4}-\left(\mathrm{NH}_{4}\right)_{2} \mathrm{SO}_{4} \\
(3: 1), \mathrm{RH}=95.9 \%\end{array}$ & References & Assignments \\
\hline 450 & 450 & 461 & Spinner (2003) & $\delta_{\mathrm{S}}\left(\mathrm{SO}_{4}^{2-}\right)$ \\
& 852 & 850 & Ebisuzaki and Angel $(1981)$ & $v(\mathrm{C}-\mathrm{C})$ \\
979 & 979 & 980 & Spinner (2003) & $v_{\mathrm{S}}\left(\mathrm{SO}_{4}^{2-}\right)$ \\
1049 & 1051 & 1050 & Dawson et al. (1986) & $v_{\mathrm{S}}\left(\mathrm{SO}_{3}\right)$ \\
& 1382 & 1382 & Chang and Huang (1997) & $\omega(\mathrm{OCO})$ \\
1446 & 1448 & 1460 & Ebisuzaki and Angel $(1981)$ & $v_{\mathrm{S}}(\mathrm{COO})$ \\
1694 & 1751 & & Ebisuzaki and Angel $(1981)$ & $v(\mathrm{C}=\mathrm{O})$ \\
1741 & 3427 & 1752 & Ebisuzaki and Angel $(1981)$ & $v(\mathrm{C}=\mathrm{O})$ \\
& & 3426 & Spinner (2003) & $v(\mathrm{OH})$ \\
\hline
\end{tabular}

$v$ : stretching, $\delta$ : bending, $\omega$ : wagging and s: symmetric mode.

(a) Dehydration, oxalic acid

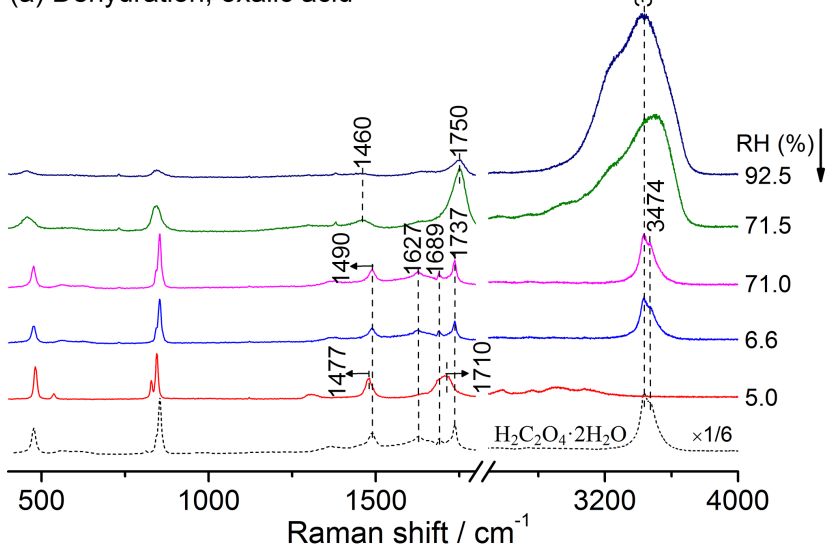

(b) Hydration, oxalic acid

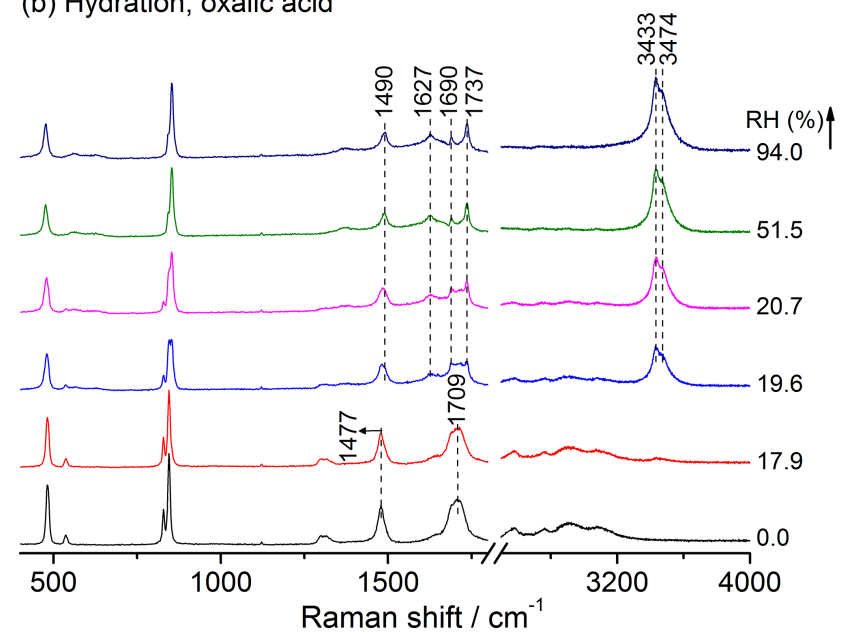

Figure 2. Raman spectra of oxalic acid (OA) droplets during the (a) dehydration process and (b) hydration process. In panel (a), the black dashed line indicates the spectrum of pure $\mathrm{H}_{2} \mathrm{C}_{2} \mathrm{O}_{4} \cdot 2 \mathrm{H}_{2} \mathrm{O}$ particles with the peak height of $v(\mathrm{OH})$ located at $3433 \mathrm{~cm}^{-1}$ scaled by a factor of $1 / 6$. cates the crystallization of AS, as also seen in Fig. 10b. A new band centered at $874 \mathrm{~cm}^{-1}$ corresponds to combination bands of the vibrational mode $(\delta(\mathrm{S}-\mathrm{OH}))$ of the $\mathrm{HSO}_{4}^{-}$ion from $\mathrm{NH}_{4} \mathrm{HSO}_{4}$ (Dawson et al., 1986) and the $\mathrm{HC}_{2} \mathrm{O}_{4}^{-}$ion vibrating (Villepin and Novak, 1971), suggesting the formation of crystalline $\mathrm{NH}_{4} \mathrm{HC}_{2} \mathrm{O}_{4}$. Moreover, the several new peaks at 1416,1469 and $1660 \mathrm{~cm}^{-1}$ can be attributed to the $\mathrm{HC}_{2} \mathrm{O}_{4}^{-}$ion vibration of crystalline $\mathrm{NH}_{4} \mathrm{HC}_{2} \mathrm{O}_{4}$ (Villepin and Novak, 1971). Therefore, the evolution of Raman spectra of the mixed OA / AS droplets (OIR = 1:3) during the dehydration process confirms that $\mathrm{OA}$ could react with $\mathrm{AS}$ to form $\mathrm{NH}_{4} \mathrm{HSO}_{4}$ and $\mathrm{NH}_{4} \mathrm{HC}_{2} \mathrm{O}_{4}$, which supports previous speculation for the reaction between OA and AS (Miñambres et al., 2013). The reaction of OA with AS occurs via the following pathway:

$$
\begin{aligned}
& \left(\mathrm{NH}_{4}\right)_{2} \mathrm{SO}_{4}(\mathrm{aq})+\mathrm{H}_{2} \mathrm{C}_{2} \mathrm{O}_{4}(\mathrm{aq}) \\
& \quad \rightarrow \mathrm{NH}_{4} \mathrm{HSO}_{4}(\mathrm{aq})+\mathrm{NH}_{4} \mathrm{HC}_{2} \mathrm{O}_{4}(\mathrm{aq}) .
\end{aligned}
$$

For the mixed OA / AS droplets (OIR = 1: 1; Fig. 3b), the evolution of spectra shows a resemblance to that of mixed droplets (OIR = 1:3). At 96.1\% RH, the peaks at 979, 1751, 1051 and $1448 \mathrm{~cm}^{-1}$ can be assigned to the vibrating mode of $\mathrm{SO}_{4}^{2-}, \mathrm{OA}, \mathrm{HSO}_{4}^{-}\left(v_{\mathrm{S}}\left(\mathrm{SO}_{3}\right)\right)$ and $\mathrm{HC}_{2} \mathrm{O}_{4}^{-}$, respectively. At $75.0 \% \mathrm{RH}$, a new peak at $874 \mathrm{~cm}^{-1}$ corresponding to the vibrational mode $(\delta(\mathrm{S}-\mathrm{OH}))$ of $\mathrm{HSO}_{4}^{-}$and the $\mathrm{HC}_{2} \mathrm{O}_{4}^{-}$ion vibrating as well as the new peaks at 494,1469 and $1677 \mathrm{~cm}^{-1}$ due to the $\mathrm{HC}_{2} \mathrm{O}_{4}^{-}$vibrating mode, indicates that crystalline $\mathrm{NH}_{4} \mathrm{HC}_{2} \mathrm{O}_{4}$ is generated from the reaction of OA with AS. As the $\mathrm{RH}$ further decreases to $44.3 \%$, the $v_{\mathrm{s}}\left(\mathrm{SO}_{4}^{2-}\right)$ band shifts from 979 to $974 \mathrm{~cm}^{-1}$, indicating the formation of crystallized AS particles.

For the mixed OA / AS droplets (OIR = 3: 1; Fig. 3c) at $95.9 \% \mathrm{RH}$, the bands at 980,1752 and $1050 \mathrm{~cm}^{-1}$ are characteristic of the $\mathrm{SO}_{4}^{2-}$ ion, OA and the $\mathrm{HSO}_{4}^{-}$ion $\left(v_{\mathrm{S}}\left(\mathrm{SO}_{3}\right)\right)$, respectively. And the peak at $1460 \mathrm{~cm}^{-1}$ can be attributed to the vibrating mode of the $\mathrm{HC}_{2} \mathrm{O}_{4}^{-}$ion. When the $\mathrm{RH}$ decreases to $74.4 \%$, a new band at $874 \mathrm{~cm}^{-1}$ is contributed by the vibrational mode of both $\mathrm{HSO}_{4}^{-}(\delta(\mathrm{S}-\mathrm{OH}))$ and $\mathrm{HC}_{2} \mathrm{O}_{4}^{-}$. 

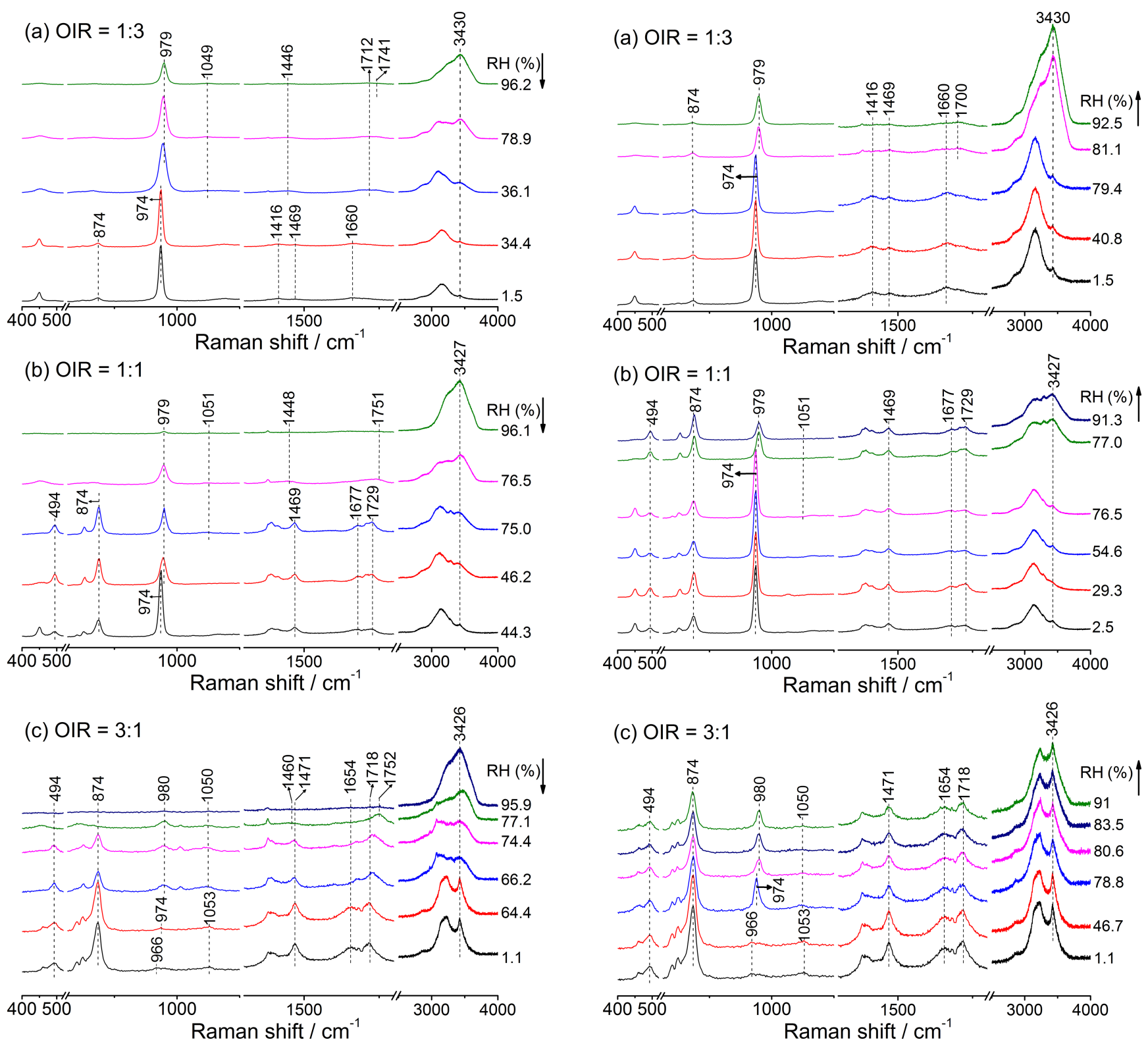

Figure 3. Raman spectra of mixed oxalic acid / ammonium sulfate (OA / AS) droplets with OIRs of (a) $1: 3$, (b) $1: 1$ and (c) $3: 1$ at various $\mathrm{RH}$ values during the dehydration process.

Meanwhile, the bands at 494, 1471 and $1654 \mathrm{~cm}^{-1}$ can be attributed to the $\mathrm{HC}_{2} \mathrm{O}_{4}^{-}$vibrating mode, suggesting $\mathrm{OA}$ reacts with AS to yield crystalline $\mathrm{NH}_{4} \mathrm{HC}_{2} \mathrm{O}_{4}$ during the dehydration process. At $64.4 \% \mathrm{RH}$, the peaks at 494,874 , $1471,1654,1718 \mathrm{~cm}^{-1}$, and the peak at $3426 \mathrm{~cm}^{-1}$ from OA dihydrate become sharp and narrow, indicating that the OA / AS droplets (OIR $=3: 1)$ completely crystallize to form $\mathrm{NH}_{4} \mathrm{HC}_{2} \mathrm{O}_{4}$ and $\mathrm{H}_{2} \mathrm{C}_{2} \mathrm{O}_{4} \cdot 2 \mathrm{H}_{2} \mathrm{O}$. No obvious change in spectral features of the major bands is observed with $\mathrm{RH}$ decreasing from 64.4 to $1.1 \%$.

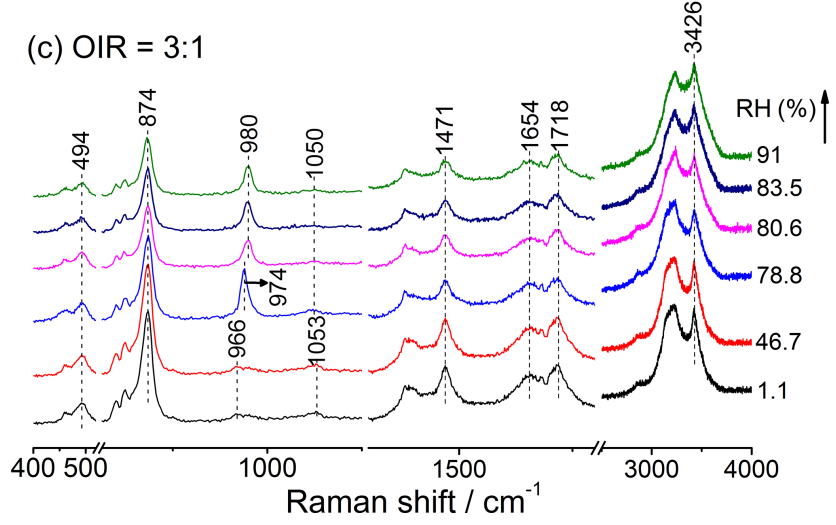

Figure 4. Raman spectra of mixed oxalic acid / ammonium sulfate (OA / AS) droplets with OIRs of (a) $1: 3$, (b) $1: 1$ and (c) $3: 1$ at various $\mathrm{RH}$ values during the hydration process.

\subsection{Hygroscopicity of pure AS, OA and OA / AS mixtures}

\subsubsection{Phase transitions and chemical transformation of AS in mixed systems}

Considering that the peak position is sensitive to the chemical environment in the aerosols, the position of the $v_{\mathrm{s}}\left(\mathrm{SO}_{4}^{2-}\right)$ mode can be used to determine the phase transitions of AS. The previous studies have also applied the abrupt shift in characteristic peak position to indicate a phase transition of AS during the hygroscopic process (Braban and Abbatt, 

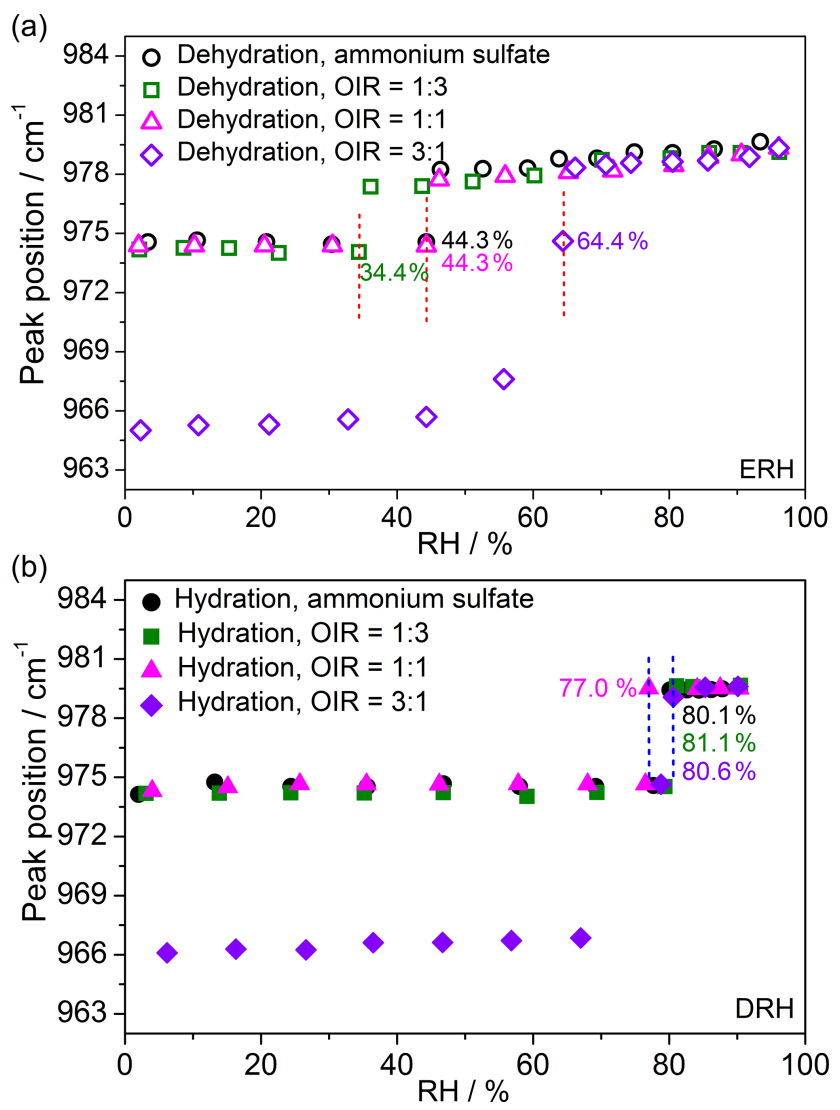

Figure 5. The peak position of the $v_{\mathrm{S}}-\mathrm{SO}_{4}^{2-}$ peak of mixed OA / AS particles and pure AS particles at various RHs during the (a) dehydration and (b) hydration process. The red and blue dashed lines indicate the ERH and DRH, respectively.

2004; Ling and Chan, 2008; Yeung et al., 2009). Figure 5 presents the peak position of the $v_{\mathrm{s}}\left(\mathrm{SO}_{4}^{2-}\right)$ for AS droplets and mixed OA / AS droplets during the dehydration and hydration processes, respectively. During the dehydration process, a red shift from 979 to $974 \mathrm{~cm}^{-1}$ can be observed for AS and OA / AS mixed particles with OIRs of $1: 3$ and $1: 1$, indicating crystallization of AS from droplets. During the hydration process, the observations of blue shift from 974 to $979 \mathrm{~cm}^{-1}$ for AS and OA / AS mixed particles with OIRs of $1: 3$ and $1: 1$ suggest the deliquescence transition of AS from crystal phase to aqueous solution. For OA / AS mixed particles with an OIR of $3: 1$, the peak shift between $\sim 966$ and $\sim 979 \mathrm{~cm}^{-1}$ is determined during the whole RH cycle. The shift of the $v_{\mathrm{s}}\left(\mathrm{SO}_{4}^{2-}\right)$ mode to $966 \mathrm{~cm}^{-1}$ suggests the formation of letovicite $\left(\mathrm{NH}_{4}\right)_{3} \mathrm{H}\left(\mathrm{SO}_{4}\right)_{2}$ (s) (Damak et al., 1985). The DRH and ERH for pure and mixed systems are shown in Fig. 5 and a detailed discussion is given in the following section.

The peaks at $\sim 1049$ and $\sim 979 \mathrm{~cm}^{-1}$ for mixed OA / AS droplets (OIRs $=1: 3,1: 1$ and $3: 1)$ can be attributed to the $\mathrm{HSO}_{4}^{-}$and $\mathrm{SO}_{4}^{2-}$ stretching mode, respectively. The area ratio of Raman peaks assigned to the $\mathrm{HSO}_{4}^{-}$and $\mathrm{SO}_{4}^{2-}$ is used
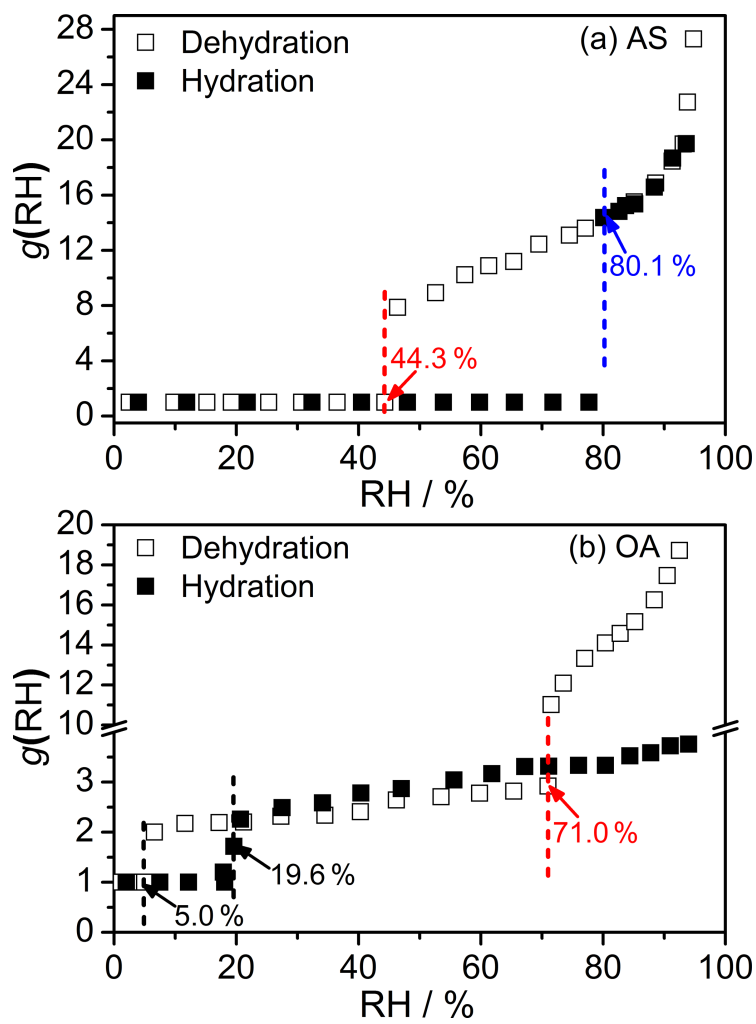

Figure 6. Hygroscopicity of (a) AS and (b) OA as a function of $\mathrm{RH}$. The red and blue dashed lines indicate the ERH and DRH, respectively. The black lines show the phase transition points for the transformation between OA dihydrate and anhydrous OA.

to indicate the degree of conversion of $\mathrm{SO}_{4}^{2-}$ into $\mathrm{HSO}_{4}^{-}$ $\left(\alpha_{\mathrm{HSO}_{4}^{-}}\right)$in mixtures, which can be expressed as the following:

$\alpha_{\mathrm{HSO}_{4}^{-}}=A_{1049} /\left(A_{1049}+A_{979}\right)$,

where $A_{1049}$ and $A_{979}$ are the peak areas of the $\mathrm{HSO}_{4}^{-}$and $\mathrm{SO}_{4}^{2-}$ signals, respectively. The peak at $\sim 1049 \mathrm{~cm}^{-1}$ for $\mathrm{HSO}_{4}^{-}$is not obvious after crystallization of the droplets. Thus, the calculations are based on the bands at RH approaching the full efflorescence point. The estimated $\alpha_{\mathrm{HSO}_{4}^{-}}$ value for OIR $=1: 3(36.1 \% \mathrm{RH}), \mathrm{OIR}=1: 1(46.2 \% \mathrm{RH})$ and $\mathrm{OIR}=3: 1(66.2 \% \mathrm{RH})$ is $0.048,0.368$ and 0.644 , respectively, indicating the enhanced conversion of $\mathrm{SO}_{4}^{2-}$ into $\mathrm{HSO}_{4}^{-}$with increasing OA content in the mixed systems. Due to the effects of the Raman cross section, $\alpha_{\mathrm{HSO}_{4}^{-}}$could not represent the actual degree of conversion. In fact, here $\alpha_{\mathrm{HSO}_{4}^{-}}$ is only used for comparisons of degree of conversion of $\mathrm{SO}_{4}^{2-}$ into $\mathrm{HSO}_{4}^{-}$between mixed particles with varying OIRs. 


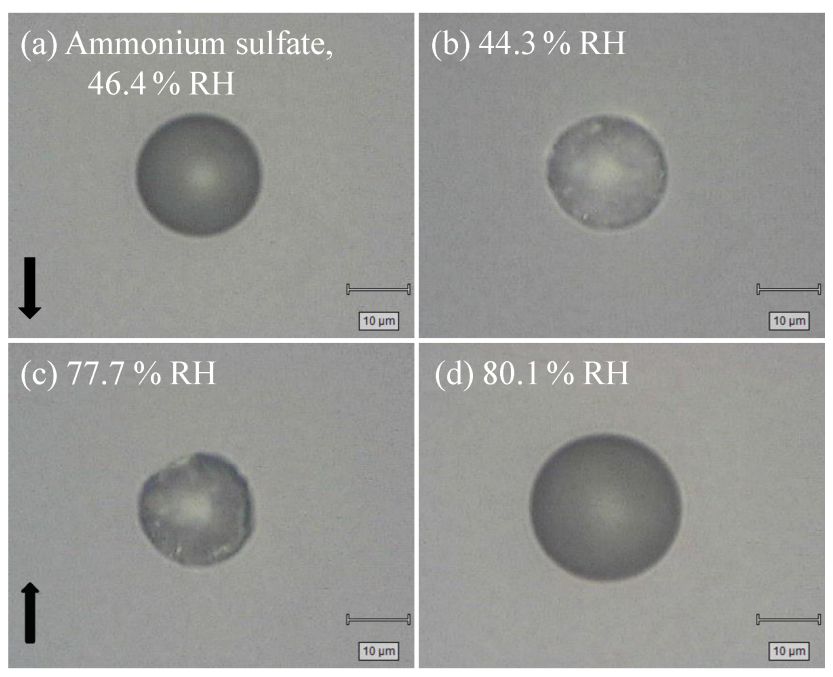

Figure 7. Optical micrographs of the ammonium sulfate (AS) particle at the phase-change points. Dehydration process: (a) $46.4 \% \mathrm{RH}$ and (b) $44.3 \%$ RH. Hydration process: (c) $77.7 \% \mathrm{RH}$ and (d) $80.1 \% \mathrm{RH}$.

\subsubsection{Hygroscopic growth of pure and mixed components}

Hygroscopicity curves of AS and OA particles are shown in Fig. 6. The optical images of the AS particle at the phase change points can be seen in Fig. 7. The ERH of AS is determined to be $44.3 \pm 2.5 \% \mathrm{RH}$, which generally falls into the range from 33 to $52 \% \mathrm{RH}$ reported in the literature (Tang and Munkelwitz, 1994a; Cziczo et al., 1997; Dougle et al., 1998; Laskina et al., 2015). The DRH of AS particles is observed to occur at $80.1 \pm 1.5 \% \mathrm{RH}$, which agrees well with reported values of $80 \%$ RH by EDB (Tang and Munkelwitz, 1994a) and $82.3 \pm 2.5 \%$ RH by micro-Raman spectroscopy (Laskina et al., 2015). As shown in Figs. 6b and 8, the measured ERH of OA is $71 \pm 2.5 \% \mathrm{RH}$, which deviates from the reported value of 51.8-56.7\% RH by Peng et al. (2001) using the EDB technology. It is worthwhile to point out that the conversion of OA droplets to OA dihydrate at $71 \% \mathrm{RH}$ is inconsistent with the observation of Peng et al. (2001). They observed that OA droplets crystallized to form anhydrous OA rather than OA dihydrate at $51.8-56.7 \% \mathrm{RH}$. The discrepancy on the ERH of OA compared to that reported by Peng et al. (2001) is likely due to the effects of substrate and sample purity. The size of dry particles ranging from 10 to $20 \mu \mathrm{m}$ in our experiment is consistent with observation using EDB by Peng et al. (2001), which eliminates the influence of particle size. The substrate supporting droplets may promote the heterogeneous nucleation of OA while the levitated droplets in the EDB study can avoid induced nucleation by the substrate. Ghorai et al. (2014) also reported the potential effects of substrate on the efflorescence transition of $\mathrm{NaCl} /$ dicarboxylic acid mixed particles. In addition, the OA

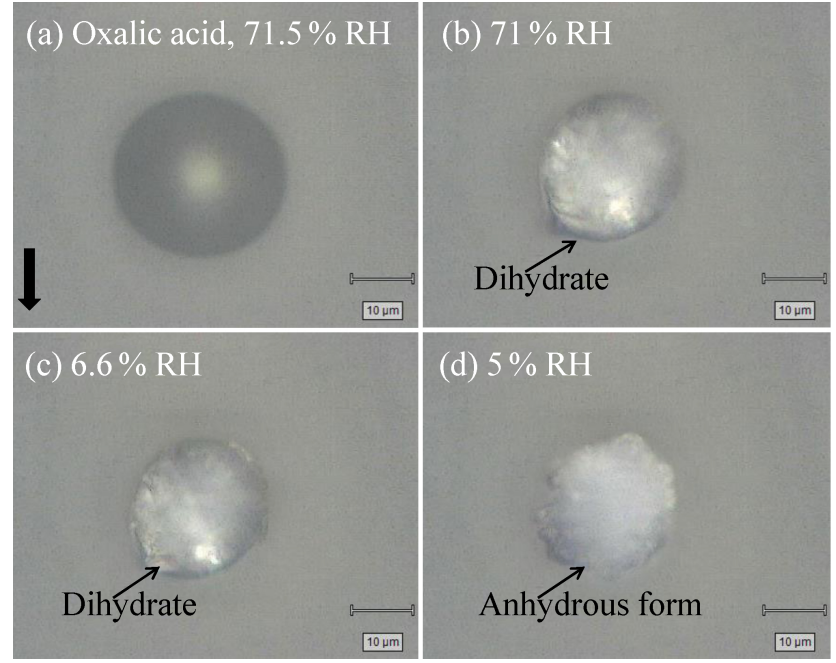

Figure 8. Optical micrographs of the oxalic acid (OA) particle at (a) $71.5 \% \mathrm{RH}$, (b) $71 \% \mathrm{RH}$, (c) $6.6 \% \mathrm{RH}$ and (d) $5 \% \mathrm{RH}$ during the dehydration process.

purity in our study is $99.0 \%$ lower than that of $99.5 \%$ in the study by Peng et al. (2001). Thus, trace amounts of impurities in OA droplets acting as a heterogeneous nucleus could contribute to crystallization and result in a higher ERH of OA. Due to the effects of substrate and sample purity, the heterogeneous nucleation should be responsible for the discrepancy on the observed ERH of OA. The water content of the supersaturated droplet at the onset of crystallization determines the form of OA crystal generated, i.e., anhydrous OA or OA dihydrate. Due to a higher ERH, OA droplets with more water content favor the formation of a dihydrate after crystallization. It should be noted that our experiment appears to be favored in the atmospheric environment, considering that insoluble material such as mineral dust mixed with OA may play the role of substrate thus facilitating the heterogeneous nucleation of OA aerosols. The Raman growth factor of OA shows no obvious change between $\sim 71$ and $6.6 \% \mathrm{RH}$ upon dehydration. At RHs lower than 5\%, the Raman growth factors drop abruptly due to the transformation of crystalline $\mathrm{H}_{2} \mathrm{C}_{2} \mathrm{O}_{4} \cdot 2 \mathrm{H}_{2} \mathrm{O}$ into anhydrous $\mathrm{OA}$, as also indicated by the Raman spectrum. It seems that the structure of the anhydrous OA particle is not as compact as that of the dihydrate, seen in Fig. 8. Thus, the loss of crystal water results in no obvious change in particle size. During the hydration process, the Raman growth factor of OA shows a slight increase at $19.6 \% \mathrm{RH}$, which can be attributed to the conversion of anhydrous OA to dihydrate. The transition point of anhydrous OA to OA dihydrate agrees with previous studies (Braban et al., 2003; Ma et al., 2013b; Miñambres et al., 2013). No deliquescence behavior is observed for OA dihydrate even at $94 \% \mathrm{RH}$, consistent with earlier observations (Ma et al., 2013b; Miñambres et al., 2013; Jing et al., 2016). 

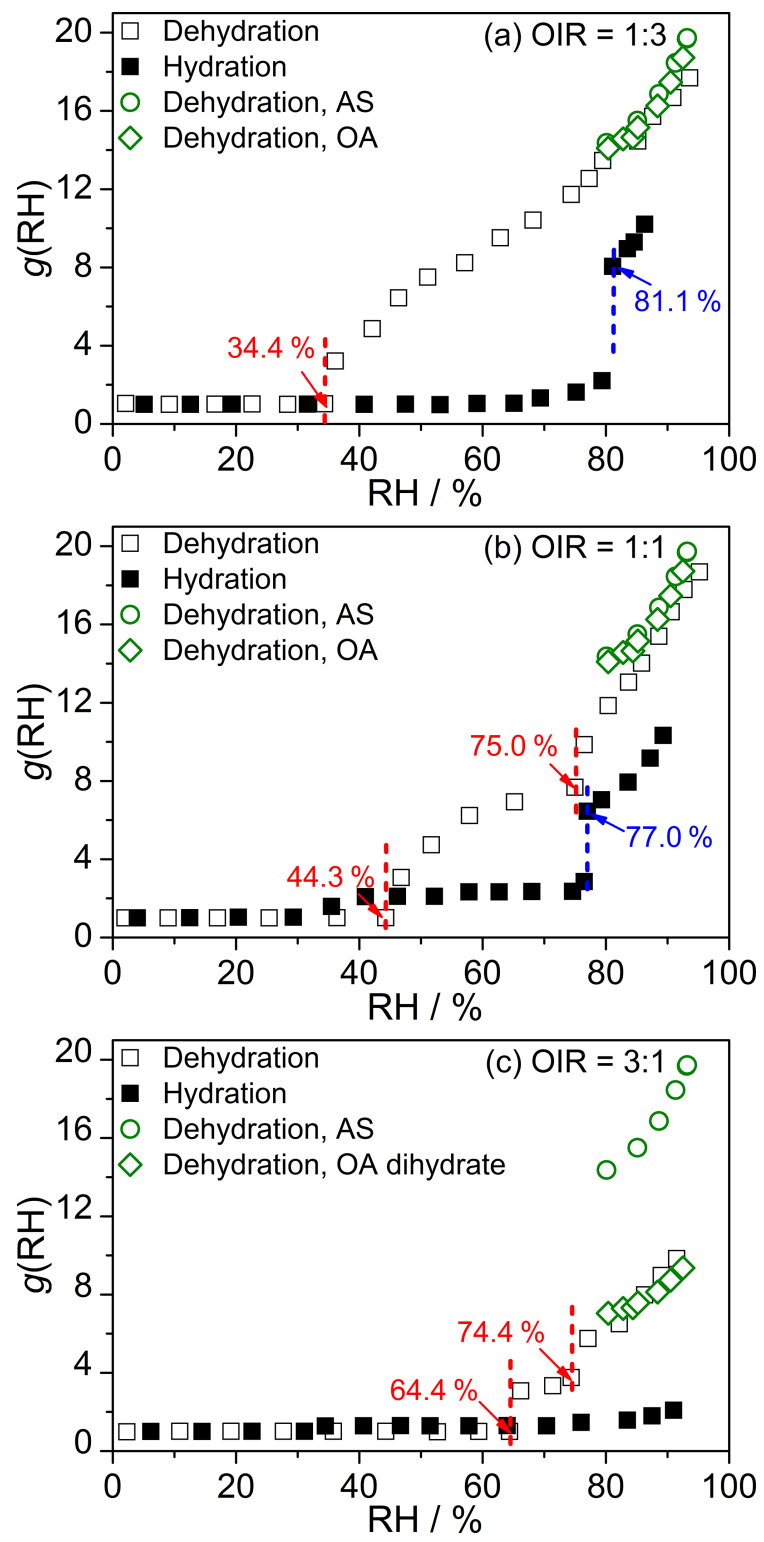

Figure 9. Hygroscopicity of OA / AS mixtures with OIRs of (a) 1 : 3, (b) $1: 1$ and (c) $3: 1$ as a function of RH. The red and blue dashed lines indicate the ERH and DRH, respectively. In panels (a) and (b), Raman growth factors of pure AS and OA above $80 \% \mathrm{RH}$ in the dehydration process are also included for comparisons. In the panel (c), Raman growth factors of pure AS and OA dihydrate above $80 \% \mathrm{RH}$ during the dehydration process are also given for comparisons.

Figure 9 presents hygroscopic growth of OA / AS mixtures with OIRs of $1: 3,1: 1$ and $3: 1$. As can be seen in Figs. 9a and 10b, mixed OA / AS droplets (OIR $=1: 3)$ exhibit efflorescence transition at lower $(34.4 \pm 2.0 \%) \mathrm{RH}$ relative to ERH $(44.3 \pm 2.5 \%)$ of pure AS. During the hydration process, mixed particles start to slightly absorb water before deliquescence at $81.1 \pm 1.5 \% \mathrm{RH}$ (seen in Figs. 9 and 10). It can be seen in Fig. 10 that the size of the $1: 3$

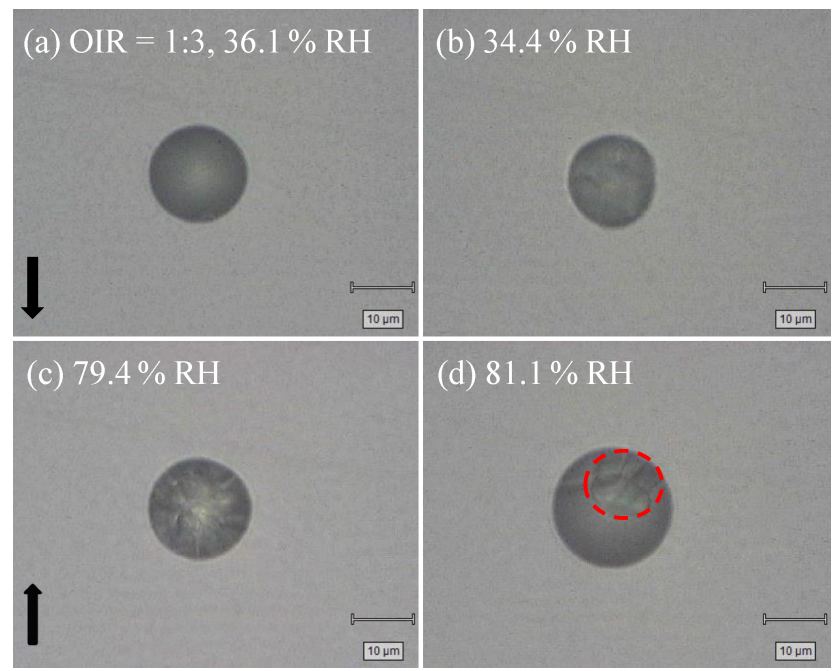

Figure 10. Optical micrographs of the mixed oxalic acid / ammonium sulfate (OA / AS) particle (OIR $=1: 3)$ at phase change points. Dehydration: (a) $36.1 \% \mathrm{RH}$ and (b) $34.4 \% \mathrm{RH}$. Hydration: (c) $79.4 \% \mathrm{RH}$ and (d) $81.1 \% \mathrm{RH}$. In the panel (d), the visual solid in aqueous phase is marked with a red dashed circle.

mixed OA / AS particle at $79.4 \%$ RH prior to deliquescence appears to be larger than that after complete efflorescence. The decrease in ERH and slight water uptake before deliquescence for $1: 3$ mixed particles is likely due to the effects of $\mathrm{NH}_{4} \mathrm{HSO}_{4}$ formed upon dehydration. $\mathrm{NH}_{4} \mathrm{HSO}_{4}$ has a low ERH (22-0.05\%) and DRH (40\%) (Tang and Munkelwitz, 1994a), which may affect the nucleation and crystallization of AS upon dehydration and lead to slight water uptake prior to the deliquescence of AS. The hygroscopic growth of mixed particles upon dehydration is in fair agreement with that of pure AS or OA. However, the Raman growth factors of mixed particles upon hydration show a considerable decrease in comparison to that upon dehydration. The discrepancies for Raman growth factor at high RH between the two processes can be attributed to the formation of $\mathrm{NH}_{4} \mathrm{HC}_{2} \mathrm{O}_{4}$ and residual solid $\mathrm{OA}$, both of which have a high deliquescence point larger than $95 \%$ RH (Schroeder and Beyer, 2016). During the hydration process, $\mathrm{NH}_{4} \mathrm{HC}_{2} \mathrm{O}_{4}$ and $\mathrm{OA}$ in the mixed aerosols remains solid even at high RH (also seen in Fig. 10d), resulting in less water uptake of mixed particles. A similar phenomenon is also observed for $\mathrm{NaCl} / \mathrm{OA}$ mixed particles upon hydration due to the formation of less hygroscopic sodium oxalate (Peng et al., 2016).

The mixed OA / AS droplets with an OIR = 1: 1 first partially effloresce at $75.0 \pm 1.6 \%$ due to the crystallization of $\mathrm{NH}_{4} \mathrm{HC}_{2} \mathrm{O}_{4}$, as indicated by Raman spectra. Then, the full efflorescence occurs at $44.3 \pm 2.5 \% \mathrm{RH}$ with the crystallization of AS. The full ERH of $1: 1 \mathrm{OA} / \mathrm{AS}$ mixed droplets is highly consistent with that of pure AS. During the hydration process, the Raman growth factor of $1: 1$ mixed particles increases slightly at $35.5 \% \mathrm{RH}$, and then remains al- 


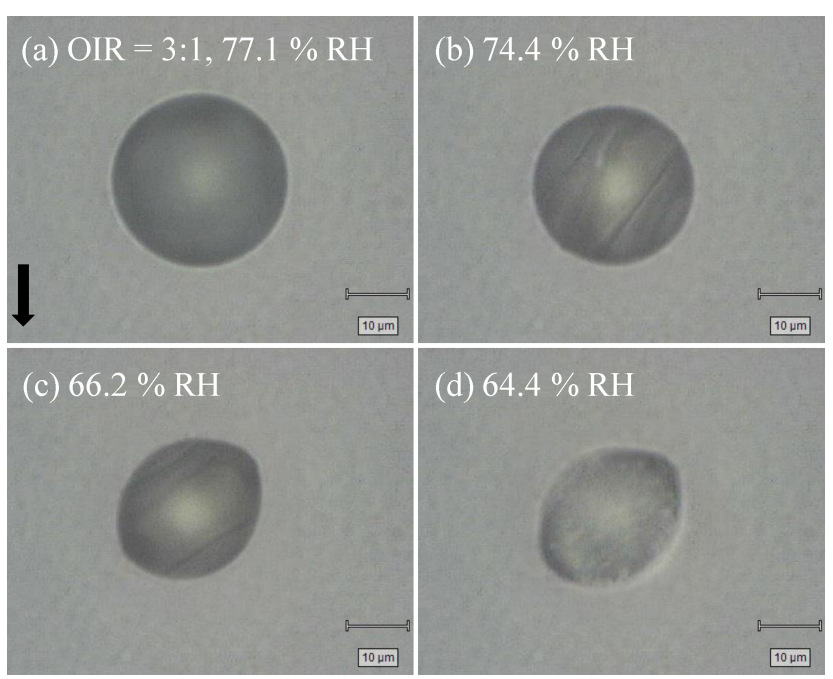

Figure 11. Optical micrographs of the mixed oxalic acid / ammonium sulfate (OA/AS) particle $(\mathrm{OIR}=3: 1)$ at (a) $77.1 \% \mathrm{RH}$, (b) $74.4 \% \mathrm{RH}$, (c) $66.2 \% \mathrm{RH}$ and (d) $64.4 \% \mathrm{RH}$ during the dehydration process.

most invariable until $77 \% \mathrm{RH}$, which is likely due to the formation of hydrate. The deliquescence transition occurs at $77 \pm 1.0 \% \mathrm{RH}$ slightly lower than DRH of AS, which agrees with literature results for AS particles containing OA (Brooks et al., 2002; Jing et al., 2016). The water contents of mixed droplets after deliquescence are significantly lower than those upon dehydration. The Raman features at 494 and $874 \mathrm{~cm}^{-1}$ have confirmed the presence of solid $\mathrm{NH}_{4} \mathrm{HC}_{2} \mathrm{O}_{4}$ upon hydration across all RHs studied (seen in Fig. 4), which should be responsible for the decreasing water uptake of the mixed particles at high RH.

For mixed OA / AS droplets with an OIR $=3: 1$, the partial and full efflorescence transition could be observed at $74.4 \pm 1.0$ and $64.4 \pm 3.0 \%$ RH, respectively (seen in Figs. 9 and 11). As seen in Fig. 3c, the bands at 494, 1471 and $1654 \mathrm{~cm}^{-1}$ suggest the formation of crystalline $\mathrm{NH}_{4} \mathrm{HC}_{2} \mathrm{O}_{4}$ at $74.4 \pm 1.0 \%$ RH. Figure 12 presents the spatial distribution of chemicals within mixed OA / AS (OIR $=3: 1)$ particles at $74.4 \% \mathrm{RH}$. The characteristic peak of 980,1050 and $1471 \mathrm{~cm}^{-1}$ is assigned to $\mathrm{SO}_{4}^{2-}, \mathrm{HSO}_{4}^{-}$and $\mathrm{HC}_{2} \mathrm{O}_{4}^{-}$, respectively. The sharp absorption at $874 \mathrm{~cm}^{-1}$ and obvious peak at $1471 \mathrm{~cm}^{-1}$ indicate the abundant content of $\mathrm{NH}_{4} \mathrm{HC}_{2} \mathrm{O}_{4}$. The comparison of characteristic peaks between inner and outer phase reveals that the major component on the surface of a mixed OA / AS (OIR =3:1) particle is $\mathrm{NH}_{4} \mathrm{HC}_{2} \mathrm{O}_{4}$. In contrast to the surface, the obvious features of 980 and $1050 \mathrm{~cm}^{-1}$ at the core of the particle suggest that $\left(\mathrm{NH}_{4}\right)_{2} \mathrm{SO}_{4}$ and $\mathrm{NH}_{4} \mathrm{HSO}_{4}$ mainly exist in the inner aqueous phase. During the dehydration process, crystalline $\mathrm{NH}_{4} \mathrm{HC}_{2} \mathrm{O}_{4}$ in the outer phase acts as the heterogeneous nucleus, leading to the crystallization of OA dihydrate and other components in the inner phase. Thus, the full ERH of $3: 1$ OA / AS mixed droplets is higher than that of pure AS $(44.3 \pm 2.5 \% \mathrm{RH})$ and $\mathrm{NH}_{4} \mathrm{HSO}_{4}(22-0.05 \% \mathrm{RH})$. During the hydration process, Raman growth factors of mixed particles slightly increase at $34.5 \%$ RH. No deliquescence transition or significant water uptake is observed over the RH range studied. This phenomenon can be explained by the fact that most of the AS in the mixtures has been converted into $\mathrm{NH}_{4} \mathrm{HC}_{2} \mathrm{O}_{4}$ and $\mathrm{NH}_{4} \mathrm{HSO}_{4}$ or letovicite. Although $\mathrm{NH}_{4} \mathrm{HSO}_{4}$ with a low DRH may contribute to water uptake of mixed particles, the minor $\mathrm{NH}_{4} \mathrm{HSO}_{4}$ or letovicite formed in the mixtures is likely to be coated by $\mathrm{NH}_{4} \mathrm{HC}_{2} \mathrm{O}_{4}$ and OA with a high DRH. Thus, the mixed OA / AS particles with an OIR $=3: 1$ show no obvious hygroscopic growth upon hydration due to the change in aerosol composition and morphology effects. The effects of morphology on the hygroscopic growth of aerosols have been reported for AS particles containing adipic acid (Sjogren et al., 2007). The water uptake of AS particles containing relatively high content of adipic acid could be suppressed due to AS enclosed by the crust of solid adipic acid with a high DRH.

The observed ERH for mixed droplets was dependent on the molar ratio of OA to AS. The mixed OA / AS droplets with an OIR of $1: 3$ are observed to effloresce completely at $34.4 \pm 2.0 \% \mathrm{RH}$ relative to ERH of pure AS $(44.3 \pm 2.5 \%)$ or OA $(71 \pm 2.5 \%)$. It can be seen that AS as a major fraction of the particle does not promote the heterogeneous nucleation of OA. Meanwhile, the crystallization of AS is also influenced due to the presence of OA. A similar phenomenon was also observed for malonic acid / AS mixtures with minor organic content (Braban and Abbatt, 2004; Parsons et al., 2004). Braban and Abbatt (2004) found that the ERH of malonic acid / AS mixed particles was considerably decreased compared to that of pure AS for mass fractions of malonic acid less than 0.3. They concluded that the presence of AS in the supersaturated droplet could exert the extra barrier to nucleation of malonic acid crystals rather than play the role of a heterogeneous nucleation site. As for $1: 3$ OA / AS mixed droplets, AS may also inhibit the nucleation of $\mathrm{OA}$ at relatively high $\mathrm{RH}$. With decreasing $\mathrm{RH}$, aqueous OA could enhance the viscosity of the droplet due to hydrogen bond interactions (Mikhailov et al., 2009), thus limiting the nucleation of AS and resulting in a lower ERH with respect to the value of pure AS (Parsons et al., 2004). In the case of mixed OA / AS droplets with an OIR of $1: 1$ and $3: 1$, the $\mathrm{NH}_{4} \mathrm{HC}_{2} \mathrm{O}_{4}$ formed at $\sim 75 \% \mathrm{RH}$ upon dehydration likely acts as a heterogeneous nucleus for crystallization of other components, which increases the full efflorescence point of mixed particles. One study indicated that humic acid sodium salt (NaHA, Aldrich) could also promote the ERH of AS (Badger et al., 2006). Similar to OA, succinic acid and adipic acid have a high deliquescence point and low solubility. However, it has been found that the efflorescence point of AS in mixed particles is not elevated even when the content of succinic acid or adipic acid is more than $50 \%$ by mass or mole fraction (Ling and Chan, 2008; Yeung et al., 2009; 


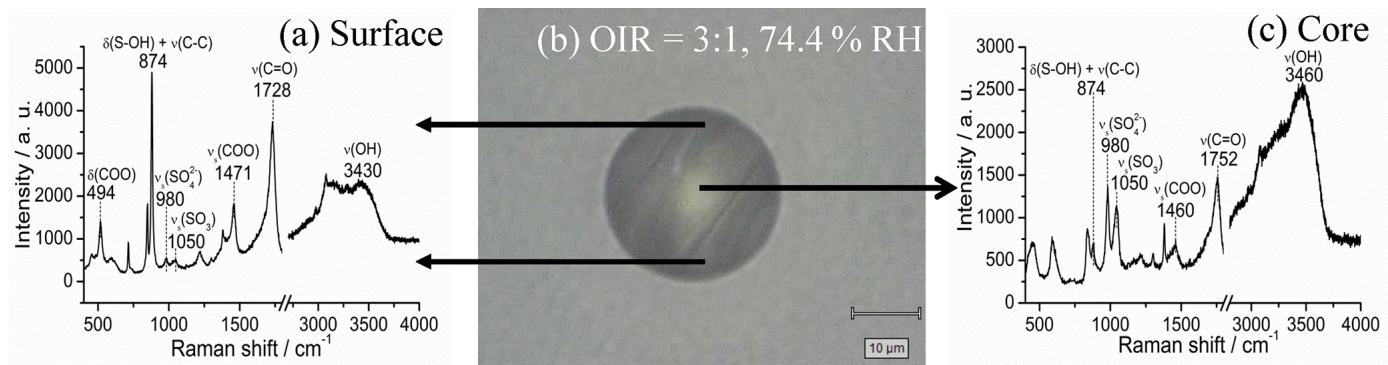

Figure 12. The spatial distribution of chemicals within mixed oxalic acid / ammonium sulfate (OIR $=3: 1)$ particles at $74.4 \% \mathrm{RH}$ upon dehydration. (a) Raman spectrum acquired on the surface showing the shell mainly consisting of $\mathrm{NH}_{4} \mathrm{HC}_{2} \mathrm{O}_{4}$. (b) Optical micrograph of a partially effloresced droplet composed of oxalic acid / ammonium sulfate (OIR = 3:1) mixtures at 74.4\% RH upon dehydration. (c) Raman spectrum obtained at the core of the droplet showing the liquid phase dominated by OA and AS.

Laskina et al., 2015). The chemical nature of a solid determines its ability to act as a heterogeneous nucleus (Braban and Abbatt, 2004). In contrast to AS particles containing succinic acid or adipic acid, our results suggest that the addition of OA into AS droplets may trigger partial and full crystallization of aerosols at relatively higher $\mathrm{RH}$ upon dehydration due to the $\mathrm{NH}_{4} \mathrm{HC}_{2} \mathrm{O}_{4}$ product acting as an effective nucleus.

During the deliquescence process, the OA / AS mixed particles with an OIR of $1: 3$ and $1: 1$ exhibit a slightly lower deliquescence point than that of pure AS, consistent with previous observations of effects of crystalline OA on deliquescence transition of AS (Brooks et al., 2002; Wise et al., 2003; Jing et al., 2016). It should be noted that prior literature results also showed that continuous or smooth water uptake from low RH was observed for particles composed of AS and OA with a mass ratio of $1.5: 1$ due to the fact that after drying OA existed in an amorphous or liquid-like state that prevented nucleation of AS even under dry conditions (Prenni et al., 2003). In the present study, water uptake by the OA / AS mixed particles at high RH upon hydration is dramatically lower than that upon dehydration and significantly decreased with elevated OA content. This phenomenon distinguishes itself from hygroscopic characteristics of typical water-soluble mixtures in the literature. It has been found that hydration growth curves and dehydration growth curves are typically merged above the deliquescence point for mixed systems containing inorganic salts and water-soluble organic compounds (Choi and Chan, 2002; Chan and Chan, 2003; Gysel et al., 2004; Clegg and Seinfeld, 2006; Sjogren et al., 2007; Pope et al., 2010; Ghorai et al., 2014; Estillore et al., 2016). In this study, Raman spectra and the micrographs suggest the presence of solid $\mathrm{NH}_{4} \mathrm{HC}_{2} \mathrm{O}_{4}$ and residual solid OA at high $\mathrm{RH}$ should be responsible for the decreased water uptake during the hydration process. In contrast, Prenni et al. (2003) reported that the hygroscopic growth of OA / AS mixed particles remained unchanged at $90 \% \mathrm{RH}$ with OA mass fraction ranging from 0.01 to 0.4 . In addition, they also found that water uptake after deliquescence was well described by the model method assuming complete dissolution of $\mathrm{OA}$ in aqueous phase as well as no interactions between OA and AS, which was also observed by Jing et al. (2016) using the HTDMA. The previous HTDMA studies for OA / AS mixed particles indicate no composition change and no specific interactions existing between OA and AS (Prenni et al., 2003; Jing et al., 2016). However, it should be noted that the HTDMA studies did not perform measurements for the dehydration process such that aerosols underwent rapid drying on the time scale of seconds, i.e., the total residence time for transformation of droplets into dry particles in the drying section of the HTDMA is typically tens of seconds (Prenni et al., 2003; Jing et al., 2016), much shorter than (10-12 h) in our study. In the HTDMA experiments, the combination of faster drying and smaller particles with submicron size implies that the aqueous phase obtained higher supersaturations than in our present study (Rosenoern et al., 2008), leading to less dissociation of $\mathrm{OA}$ and thus less $\mathrm{HC}_{2} \mathrm{O}_{4}^{-}$formed in the droplets as well as the inhibited formation of $\mathrm{NH}_{4} \mathrm{HC}_{2} \mathrm{O}_{4}$. The fast evaporation of water from the surface of an aqueous droplet upon rapid drying could result in a higher surface concentration of solutes than the slow drying process (Treuel et al., 2011). The higher surface concentration of OA corresponds to less formation and hence decreased supersaturation of $\mathrm{HC}_{2} \mathrm{O}_{4}^{-}$. Due to the dependence of the nucleation rate on the extent of supersaturation, it can be expected that the nucleation of $\mathrm{NH}_{4} \mathrm{HC}_{2} \mathrm{O}_{4}$ is suppressed within OA / AS mixed droplets undergoing rapid drying.

Considering the potential effects of drying time on the reactions between OA and AS, we explored the hygroscopicity of OA / AS particles with an OIR of $1: 1$ after the rapid drying process. The mixed OA / AS droplets undergo dehydration to form dry particles in $3-5 \mathrm{~min}$. We observed one-step efflorescence of rapidly dried particles ( 1 : 1 , molar ratio) occurring at $47 \pm 2.5 \% \mathrm{RH}$, compared to the two-step efflorescence of slowly dried particles occurring at 75 and $44.3 \% \mathrm{RH}$. The Raman spectra and hygroscopic curve upon hydration for OA / AS particles with an OIR of $1: 1$ are presented in Fig. 13. The obvious discrepancies can be observed for spectra at $\sim 2 \% \mathrm{RH}$ between 

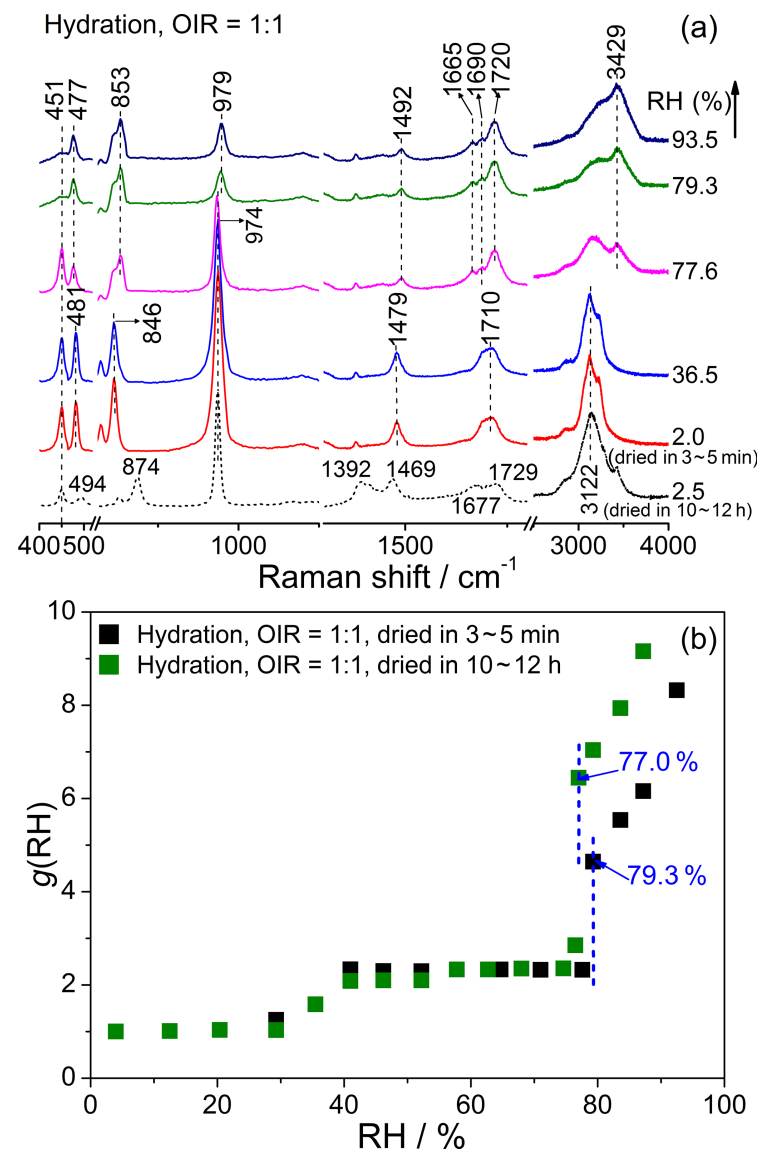

Figure 13. (a) Raman spectra of equal molar mixed OA / AS particles after the rapid drying process at various $\mathrm{RH}$ values upon hydration. The Raman spectrum (black short dash) at $2.5 \% \mathrm{RH}$ obtained from the slow drying process is also given for comparison. (b) Deliquescence curve of OA / AS mixtures with an OIR of $1: 1$. The hygroscopic curve (olive symbols) of particles after the slow drying process is also included for comparison. The blue dashed lines indicate the DRH.

the two drying processes. After the rapid drying process, the spectra at $\sim 2 \% \mathrm{RH}$ show the feature of crystalline AS $\left(974 \mathrm{~cm}^{-1}: v_{\mathrm{s}}\left(\mathrm{SO}_{4}^{2-}\right)\right)$ and anhydrous OA $\left(1710 \mathrm{~cm}^{-1}\right.$ : $\left.v(\mathrm{C}=\mathrm{O}), 1479 \mathrm{~cm}^{-1}: v_{\mathrm{S}}(\mathrm{COO})\right)$. Meanwhile, no characteristic peaks for $\mathrm{NH}_{4} \mathrm{HC}_{2} \mathrm{O}_{4}\left(494 \mathrm{~cm}^{-1}: \delta(\mathrm{COO}), 874 \mathrm{~cm}^{-1}\right.$ : $\left.v(\mathrm{C}-\mathrm{C}), 1729 \mathrm{~cm}^{-1}: v(\mathrm{C}=\mathrm{O}), 1469 \mathrm{~cm}^{-1}: v_{\mathrm{s}}(\mathrm{COO})\right)$ and $\mathrm{NH}_{4} \mathrm{HSO}_{4}\left(874 \mathrm{~cm}^{-1}: \delta(\mathrm{S}-\mathrm{OH})\right)$ can be identified in the spectra. It is clear that the drying time for transformation of droplets into dry particles has an impact on the reactions of OA with AS in the aerosols due to particle-phase processes under kinetic control. Previous studies found the longer drying time could lead to greater nitrate depletion between nitrates and organic acids, which results from slow reaction and diffusion in the viscous aerosols (Wang and Laskin, 2014). The Raman growth factors of mixed particles with an OIR of $1: 1$ also increase slightly at $36.5 \% \mathrm{RH}$ due to the formation of OA dihydrate, as indicated by the Raman feature. The deli- quescence transition of mixed particles occurs at $79.3 \% \mathrm{RH}$. After deliquescence, Raman growth factors of mixed particles after the rapid drying process are lower than that after the slow drying process, which may be caused by the fact that at high $\mathrm{RH}$ the hygroscopic growth of AS is slightly lower than that of $\mathrm{NH}_{4} \mathrm{HSO}_{4}$ formed in the particles after the slow drying process (Tang and Munkelwitz, 1977). In addition, it is found that after deliquescence OA dihydrate remains solid in the mixed particles undergoing rapid drying.

\section{Conclusions and atmospheric implications}

In this work, confocal Raman spectroscopy is used to investigate the hygroscopic properties and phase transformations of OA and internally mixed OA / AS droplets (OIRs $=1: 3$, $1: 1$ and $3: 1$ ). OA droplets effloresce to form OA dihydrate at $71 \pm 2.5 \% \mathrm{RH}$, and then OA dihydrate further loses crystalline water to form anhydrous $\mathrm{OA}$ at $\sim 5.0 \% \mathrm{RH}$ during the dehydration process. The Raman spectra of mixed $\mathrm{OA} / \mathrm{AS}$ droplets reveal the formation of $\mathrm{NH}_{4} \mathrm{HC}_{2} \mathrm{O}_{4}$ and $\mathrm{NH}_{4} \mathrm{HSO}_{4}$ from the reaction of OA with $\mathrm{AS}$ in aerosols during the dehydration process. The deliquescence and efflorescence point for AS is observed to occur at $80.1 \pm 1.5$ and $44.3 \pm 2.5 \% \mathrm{RH}$, respectively. The ERH of the mixed OA / AS droplets with $1: 3,1: 1$ and $3: 1$ ratios is determined to be $34.4 \pm 2.0,44.3 \pm 2.5$ and $64.4 \pm 3.0 \% \mathrm{RH}$, respectively, indicating significant effects of OA content on the efflorescence transition of AS. The mixed OA / AS particles with $1: 3$ and $1: 1$ ratios show deliquescence transitions at $81.1 \pm 1.5$ and $77 \pm 1.0 \% \mathrm{RH}$, respectively, which is close to the DRH of AS. The mixed OA / AS particles with $3: 1$ ratio exhibit no deliquescence transition over the $\mathrm{RH}$ range studied due to the transformation of $\left(\mathrm{NH}_{4}\right)_{2} \mathrm{SO}_{4}$ into high-DRH $\mathrm{NH}_{4} \mathrm{HC}_{2} \mathrm{O}_{4}$. The hygroscopic growth of mixed particles at high $\mathrm{RH}$ upon hydration is substantially lower than that of the corresponding dehydration process and further decreases with increasing OA content. The discrepancies for water content of mixed particles between the two processes at high RH can be explained by the significant formation of low hygroscopic $\mathrm{NH}_{4} \mathrm{HC}_{2} \mathrm{O}_{4}$ and residual OA, which still remain solid and thus result in less water uptake of mixed particles.

The prior hygroscopic studies suggest that crystallization of internally mixed AS / dicarboxylic acid particles may lead to the formation of trace organic salt. Lightstone et al. (2000) estimated that approximately $2 \%$ of the initial succinic acid may form ammoniated succinate within mixed ammonium nitrate / succinic acid particles during the efflorescence process. Ling and Chan (2008) inferred that crystallization of AS / succinic acid droplets likely generated metastable organic salt based on a change in the Raman peak form of succinic acid. Braban and Abbatt (2004) reported that $\mathrm{NH}_{4} \mathrm{HSO}_{4}$ and ammoniated malonate were likely generated upon crystallization of mixed AS / malonic acid particles. However, due to the trace amount of organic salt below the 
Raman or infrared detection limit, they found no apparent influence of organic salt formed upon dehydration on the water uptake or phase change of mixed particles. In contrast, our results indicate that the chemical processing upon drying of droplets containing OA and AS influences the efflorescence transition and water uptake of mixed aerosols during the humidity cycle by modifying particulate components.

Our results highlight the atmospheric importance of dicarboxylic acid-AS interactions in aerosol aqueous chemistry. Such chemical processing upon drying of aerosols comprised of organic acid / $\left(\mathrm{NH}_{4}\right)_{2} \mathrm{SO}_{4}$ mixtures may enhance the acidity of the aqueous phase in the intermediate $\mathrm{RH}$ due to the transformation of $\left(\mathrm{NH}_{4}\right)_{2} \mathrm{SO}_{4}$ into $\mathrm{NH}_{4} \mathrm{HSO}_{4}$. These experiments also imply that the chemical reaction between aqueous $\left(\mathrm{NH}_{4}\right)_{2} \mathrm{SO}_{4}$ and $\mathrm{OA}$ upon slow dehydration is a possible formation pathway for the low-volatility oxalate in ambient particles, which could enhance partitioning of dicarboxylic acids to aqueous particles with the presence of AS (Yli-Juuti et al., 2013; Hakkinen et al., 2014). It has been reported that the aerosol aqueous processing within organic acid / AS mixtures partly contributes to enhanced loadings of secondary organic aerosol from biogenic precursors (Hoyle et al., 2011). Compared to aqueous processing such as condensed-phase acid-catalyzed reactions relevant to formation of organosulfates, the contribution of other aerosol processes containing organic salt formation to secondary organic aerosol burden likely becomes important under less acidic conditions. Formation of low-solubility organic salts from aqueous processing within aerosols alters the particlephase component and thus modifies aerosol's hygroscopicity, optical properties and chemical reactivity. Our findings provide fundamental insights into the effects of drying conditions (drying rate or time) on formation of organic salts from reactions of organic acids with inorganic salts in the particle phase under ambient RH conditions. Overall, a better understanding of the chemical interactions between species in a multicomponent system during the humidity cycle is critical for the accurate modeling efforts of aerosol phase behavior in thermodynamic models.

Data availability. All data are available upon request from the corresponding authors.

Author contributions. YZ, MG and BJ designed the experiments and XW carried them out. XW and BJ performed the data analysis and prepared the manuscript with contributions from all co-authors.

Competing interests. The authors declare that they have no conflict of interest.
Acknowledgements. This project was supported by the National Natural Science Foundation of China (contract no. 91544223, 21473009 and 21373026) and the National Key Research and Development Program of China (2016YFC0202202).

Edited by: Markus Petters

Reviewed by: Gregory Schill and two anonymous referees

\section{References}

Amundson, N. R., Caboussat, A., He, J. W., Martynenko, A. V., and Seinfeld, J. H.: A phase equilibrium model for atmospheric aerosols containing inorganic electrolytes and organic compounds (UHAERO), with application to dicarboxylic acids, J. Geophys. Res.-Atmos., 112, D24S13, https://doi.org/10.1029/2007jd008424, 2007.

Badger, C. L., George, I., Griffiths, P. T., Braban, C. F., Cox, R. A., and Abbatt, J. P. D.: Phase transitions and hygroscopic growth of aerosol particles containing humic acid and mixtures of humic acid and ammonium sulphate, Atmos. Chem. Phys., 6, 755-768, https://doi.org/10.5194/acp-6-755-2006, 2006.

Braban, C. F. and Abbatt, J. P. D.: A study of the phase transition behavior of internally mixed ammonium sulfate malonic acid aerosols, Atmos. Chem. Phys., 4, 1451-1459, https://doi.org/10.5194/acp-4-1451-2004, 2004.

Braban, C. F., Carroll, M. F., Styler, S. A., and Abbatt, J. P. D.: Phase transitions of malonic and oxalic acid aerosols, J. Phys. Chem. A, 107, 6594-6602, https://doi.org/10.1021/jp034483f, 2003.

Brooks, S. D., Wise, M. E., Cushing, M., and Tolbert, M. A.: Deliquescence behavior of organic/ammonium sulfate aerosol, Geophys. Res. Lett., 29, 1917, https://doi.org/10.1029/2002gl014733, 2002.

Chan, M. N. and Chan, C. K.: Hygroscopic properties of two model humic-like substances and their mixtures with inorganics of atmospheric importance, Environ. Sci. Technol., 37, 5109-5115, https://doi.org/10.1021/es034272o, 2003.

Chang, H. and Huang, P. J.: Thermal decomposition of $\mathrm{CaC}_{2} \mathrm{O}_{4}^{\cdot} \mathrm{H}_{2} \mathrm{O}$ studied by thermo-Raman spectroscopy with TGA/DTA, Anal. Chem., 69, 1485-1491, https://doi.org/10.1021/ac9608811, 1997.

Chebbi, A. and Carlier, P.: Carboxylic acids in the troposphere, occurrence, sources, and sinks: A review, Atmos. Environ., 30, 4233-4249, https://doi.org/10.1016/1352-2310(96)00102-1, 1996.

Choi, M. Y. and Chan, C. K.: The effects of organic species on the hygroscopic behaviors of inorganic aerosols, Environ. Sci. Technol., 36, 2422-2428, https://doi.org/10.1021/es0113293, 2002.

Clegg, S. L. and Seinfeld, J. H.: Thermodynamic models of aqueous solutions containing inorganic electrolytes and dicarboxylic acids at $298.15 \mathrm{~K}$. 1. The acids as nondissociating components, J. Phys. Chem. A, 110, 5692-5717, https://doi.org/10.1021/jp056149k, 2006.

Cziczo, D. J., Nowak, J. B., Hu, J. H., and Abbatt, J. P. D.: Infrared spectroscopy of model tropospheric aerosols as a function of relative humidity: Observation of deliquescence and crystallization, J. Geophys. Res., 102, 18843-18850, https://doi.org/10.1029/97jd01361, 1997. 
Damak, M., Kamoun, M., Daoud, A., Romain, F., Lautie, A., and Novak, A.: Vibrational study of hydrogen bonding and structural disorder in $\mathrm{Na} 3 \mathrm{H}_{(}\left(\mathrm{SO}_{4}\right)_{2}, \mathrm{~K}_{3} \mathrm{H}\left(\mathrm{SO}_{4}\right)_{2}$ and $\left(\mathrm{NH}_{4}\right)_{3} \mathrm{H}\left(\mathrm{SO}_{4}\right)_{2}$ crystals, J. Mol. Struct., 130, 245-254, https://doi.org/10.1016/0022-2860(85)87006-X, 1985.

Dawson, B. S. W., Irish, D. E., and Toogood, G. E.: Vibrational spectral studies of solutions at elevated temperatures and pressures. 8. A Raman spectral study of ammonium hydrogen sulfate solutions and the $\mathrm{HSO}_{4}^{-}-\mathrm{SO}_{4}^{2-}$ equilibrium, J. Phys. Chem., 90, 334-341, https://doi.org/10.1021/j100274a027, 1986.

Dong, J. L., Xiao, H. S., Zhao, L. J., and Zhang, Y. H.: Spatially resolved Raman investigation on phase separations of mixed $\mathrm{Na}_{2} \mathrm{SO}_{4} / \mathrm{MgSO}_{4}$ droplets, J. Raman Spectrosc., 40, 338-343, https://doi.org/10.1002/jrs.2132, 2009.

Dougle, P. G., Veefkind, J. P., and ten Brink, H. M.: Crystallisation of mixtures of ammonium nitrate, ammonium sulphate and soot, J. Aerosol Sci., 29, 375-386, https://doi.org/10.1016/S00218502(97)10003-9, 1998.

Drozd, G., Woo, J., Häkkinen, S. A. K., Nenes, A., and McNeill, V. F.: Inorganic salts interact with oxalic acid in submicron particles to form material with low hygroscopicity and volatility, Atmos. Chem. Phys., 14, 5205-5215, https://doi.org/10.5194/acp14-5205-2014, 2014.

Ebisuzaki, Y. and Angel, S. M.: Raman study of hydrogen bonding in $\alpha$ and $\beta$-oxalic acid dihydrate, J. Raman Spectrosc., 11, 306311, https://doi.org/10.1002/jrs.1250110416, 1981.

Estillore, A. D., Hettiyadura, A. P. S., Qin, Z., Leckrone, E., Wombacher, B., Humphry, T., Stone, E. A., and Grassian, V. H.: Water uptake and hygroscopic growth of organosulfate aerosol, Environ. Sci. Technol., 50, 4259-4268, https://doi.org/10.1021/acs.est.5b05014, 2016.

Ghorai, S., Wang, B., Tivanski, A., and Laskin, A.: Hygroscopic properties of internally mixed particles composed of $\mathrm{NaCl}$ and water-soluble organic acids, Environ. Sci. Technol., 48, 22342241, https://doi.org/10.1021/es404727u, 2014.

Gysel, M., Weingartner, E., Nyeki, S., Paulsen, D., Baltensperger, U., Galambos, I., and Kiss, G.: Hygroscopic properties of water-soluble matter and humic-like organics in atmospheric fine aerosol, Atmos. Chem. Phys., 4, 35-50, https://doi.org/10.5194/acp-4-35-2004, 2004.

Hakkinen, S. A. K., McNeill, V. F., and Riipinen, I.: Effect of inorganic salts on the volatility of organic acids, Environ. Sci. Technol., 48, 13718-13726, https://doi.org/10.1021/es5033103, 2014.

Hibben, J. H.: The Raman spectra of oxalic acid, J. Chem. Phys., 3, 675-679, https://doi.org/10.1063/1.1749575, 1935.

Hoyle, C. R., Boy, M., Donahue, N. M., Fry, J. L., Glasius, M., Guenther, A., Hallar, A. G., Huff Hartz, K., Petters, M. D., Petäjä, T., Rosenoern, T., and Sullivan, A. P.: A review of the anthropogenic influence on biogenic secondary organic aerosol, Atmos. Chem. Phys., 11, 321-343, https://doi.org/10.5194/acp-11-3212011, 2011.

Jacobson, M. C., Hansson, H. C., Noone, K. J., and Charlson, R. J.: Organic atmospheric aerosols: Review and state of the science, Rev. Geophys., 38, 267-294, https://doi.org/10.1029/1998RG000045, 2000.

Jing, B., Tong, S., Liu, Q., Li, K., Wang, W., Zhang, Y., and Ge, M.: Hygroscopic behavior of multicomponent organic aerosols and their internal mixtures with ammonium sulfate, Atmos.
Chem. Phys., 16, 4101-4118, https://doi.org/10.5194/acp-164101-2016, 2016.

Jing, B., Peng, C., Wang, Y. D., Liu, Q. F., Tong, S. R., Zhang, Y. H., and Ge, M. F.: Hygroscopic properties of potassium chloride and its internal mixtures with organic compounds relevant to biomass burning aerosol particles, Sci. Rep., 7, 43572, https://doi.org/10.1038/srep43572, 2017.

Kanakidou, M., Seinfeld, J. H., Pandis, S. N., Barnes, I., Dentener, F. J., Facchini, M. C., Van Dingenen, R., Ervens, B., Nenes, A., Nielsen, C. J., Swietlicki, E., Putaud, J. P., Balkanski, Y., Fuzzi, S., Horth, J., Moortgat, G. K., Winterhalter, R., Myhre, C. E. L., Tsigaridis, K., Vignati, E., Stephanou, E. G., and Wilson, J.: Organic aerosol and global climate modelling: a review, Atmos. Chem. Phys., 5, 1053-1123, https://doi.org/10.5194/acp-5-10532005, 2005.

Kawamura, K. and Bikkina, S.: A review of dicarboxylic acids and related compounds in atmospheric aerosols: Molecular distributions, sources and transformation, Atmos. Res., 170, 140-160, https://doi.org/10.1016/j.atmosres.2015.11.018, 2016.

Laskin, A., Moffet, R. C., Gilles, M. K., Fast, J. D., Zaveri, R. A., Wang, B., Nigge, P., and Shutthanandan, J.: Tropospheric chemistry of internally mixed sea salt and organic particles: Surprising reactivity of $\mathrm{NaCl}$ with weak organic acids, J. Geophys. Res., 117, D15302, https://doi.org/10.1029/2012jd017743, 2012.

Laskina, O., Young, M. A., Kleiber, P. D., and Grassian, V. H.: Infrared extinction spectroscopy and micro-Raman spectroscopy of select components of mineral dust mixed with organic compounds, J. Geophys. Res., 118, 6593-6606, https://doi.org/10.1002/jgrd.50494, 2013.

Laskina, O., Morris, H. S., Grandquist, J. R., Qin, Z., Stone, E. A., Tivanski, A. V., and Grassian, V. H.: Size matters in the water uptake and hygroscopic growth of atmospherically relevant multicomponent aerosol particles, J. Phys. Chem. A, 119, 4489-4497, https://doi.org/10.1021/jp510268p, 2015.

Li, X., Gupta, D., Lee, J., Park, G., and Ro, C. U.: Real-time investigation of chemical compositions and hygroscopic properties of aerosols generated from $\mathrm{NaCl}$ and malonic acid mixture solutions using in situ Raman microspectrometry, Environ. Sci. Technol., 51, 263-270, https://doi.org/10.1021/acs.est.6b04356, 2017.

Lightstone, J. M., Onasch, T. B., Imre, D., and Oatis, S.: Deliquescence, efflorescence, and water activity in ammonium nitrate and mixed ammonium nitrate/succinic acid microparticles, J. Phys. Chem. A, 104, 9337-9346, https://doi.org/10.1021/jp002137h, 2000.

Ling, T. Y. and Chan, C. K.: Partial crystallization and deliquescence of particles containing ammonium sulfate and dicarboxylic acids, J. Geophys. Res: Atmos., 113, D14205, https://doi.org/10.1029/2008JD009779, 2008.

Liu, Y., Yang, Z. W., Desyaterik, Y., Gassman, P. L., Wang, H., and Laskin, A.: Hygroscopic behavior of substrate-deposited particles studied by micro-FT-IR spectroscopy and complementary methods of particle analysis, Anal. Chem., 80, 633-642, https://doi.org/10.1021/ac701638r, 2008.

Ma, Q. and He, H.: Synergistic effect in the humidifying process of atmospheric relevant calcium nitrate, calcite and oxalic acid mixtures, Atmos. Environ., 50, 97-102, https://doi.org/10.1016/j.atmosenv.2011.12.057, 2012. 
Ma, Q., He, H., and Liu, C.: Hygroscopic properties of oxalic acid and atmospherically relevant oxalates, Atmos. Environ., 69, 281288, https://doi.org/10.1016/j.atmosenv.2012.12.011, 2013a.

Ma, Q., Ma, J., Liu, C., Lai, C., and He, H.: Laboratory study on the hygroscopic behavior of external and internal $\mathrm{C}_{2}-\mathrm{C}_{4}$ dicarboxylic acid-NaCl mixtures, Environ. Sci. Technol., 47, 1038110388, https://doi.org/10.1021/es4023267, 2013b.

Mikhailov, E., Vlasenko, S., Martin, S. T., Koop, T., and Pöschl, U.: Amorphous and crystalline aerosol particles interacting with water vapor: conceptual framework and experimental evidence for restructuring, phase transitions and kinetic limitations, Atmos. Chem. Phys., 9, 9491-9522, https://doi.org/10.5194/acp-9-94912009, 2009.

Miñambres, L., Méndez, E., Sánchez, M. N., Castaño, F., and Basterretxea, F. J.: Water uptake of internally mixed ammonium sulfate and dicarboxylic acid particles probed by infrared spectroscopy, Atmos. Environ., 70, 108-116, https://doi.org/10.1016/j.atmosenv.2013.01.007, 2013.

Mohaček-Grošev, V., Grdadolnik, J., Stare, J., and Hadži, D.: Identification of hydrogen bond modes in polarized Raman spectra of single crystals of $\alpha$-oxalic acid dihydrate, J. Raman Spectrosc., 40, 1605-1614, https://doi.org/10.1002/jrs.2308, 2009.

Murphy, D. M., Thomson, D. S., and Mahoney, M. J.: In situ measurements of organics, meteoritic material, mercury, and other elements in aerosols at 5 to 19 kilometers, Science, 282, 16641669, https://doi.org/10.1126/science.282.5394.1664, 1998.

Murphy, D. M., Cziczo, D. J., Froyd, K. D., Hudson, P. K., Matthew, B. M., Middlebrook, A. M., Peltier, R. E., Sullivan, A., Thomson, D. S., and Weber, R. J.: Single-particle mass spectrometry of tropospheric aerosol particles, J. Geophys. Res., 111, D23S32, https://doi.org/10.1029/2006JD007340, 2006.

Parsons, M. T., Knopf, D. A., and Bertram, A. K.: Deliquescence and crystallization of ammonium sulfate particles internally mixed with water-soluble organic compounds, J. Phys. Chem. A, 108, 11600-11608, https://doi.org/10.1021/jp0462862, 2004.

Peng, C., Jing, B., Guo, Y. C., Zhang, Y. H., and Ge, M. F.: Hygroscopic behavior of multicomponent aerosols involving $\mathrm{NaCl}$ and dicarboxylic acids, J. Phys. Chem. A, 120, 1029-1038, https://doi.org/10.1021/acs.jpca.5b09373, 2016.

Peng, C. G., Chan, M. N., and Chan, C. K.: The hygroscopic properties of dicarboxylic and multifunctional acids: Measurements and UNIFAC predictions, Environ. Sci. Technol., 35, 4495-4501, https://doi.org/10.1021/es0107531, 2001.

Penner, J. E., Andreae, M. O., Annegarn, H., Barrie, L., Feichter, J., Hegg, D., Jayaraman, A., Leaitch, R., Murphy, D., Nganga, J., and Pitari, G.: Aerosols, their direct and indirect effects, in: Climate Change 2001: The Scientific Basis. Contribution of Working Group I to the Third Assessment Report of the Intergovernmental Panel on Climate Change, Cambridge University Press, 289-348, 2001.

Pope, F. D., Dennis-Smither, B. J., Griffiths, P. T., Clegg, S. L., and Cox, R. A.: Studies of single aerosol particles containing malonic acid, glutaric acid, and their mixtures with sodium chloride. I. Hygroscopic growth, J. Phys. Chem. A, 114, 5335-5341, https://doi.org/10.1021/jp100059k, 2010.

Pöschl, U.: Atmospheric aerosols: composition, transformation, climate and health effects, Angew. Chem. Int. Ed., 44, 7520-7540, https://doi.org/10.1002/anie.200501122, 2005.
Pradeep Kumar, P., Broekhuizen, K., and Abbatt, J. P. D.: Organic acids as cloud condensation nuclei: Laboratory studies of highly soluble and insoluble species, Atmos. Chem. Phys., 3, 509-520, https://doi.org/10.5194/acp-3-509-2003, 2003.

Pratt, K. A. and Prather, K. A.: Aircraft measurements of vertical profiles of aerosol mixing states, J. Geophys. Res., 115, D11305, https://doi.org/10.1029/2009JD013150, 2010.

Prenni, A. J., DeMott, P. J., and Kreidenweis, S. M.: Water uptake of internally mixed particles containing ammonium sulfate and dicarboxylic acids, Atmos. Environ., 37, 4243-4251, https://doi.org/10.1016/S1352-2310(03)00559-4, 2003.

Rosenoern, T., Schlenker, J. C., and Martin, S. T.: Hygroscopic growth of multicomponent aerosol particles influenced by several cycles of relative humidity, J. Phys. Chem. A, 112, 2378-2385, https://doi.org/10.1021/jp0771825, 2008.

Saxena, P., Hildemann, L. M., McMurry, P. H., and Seinfeld, J. H.: Organics alter hygroscopic behavior of atmospheric particles, J. Geophys. Res., 100, 18755-18770, https://doi.org/10.1029/95JD01835, 1995.

Schroeder, J. R. and Beyer, K. D.: Deliquescence relative humidities of organic and inorganic salts important in the atmosphere, J. Phys. Chem. A, 120, 9948-9957, https://doi.org/10.1021/acs.jpca.6b08725, 2016.

Sjogren, S., Gysel, M., Weingartner, E., Baltensperger, U., Cubison, M. J., Coe, H., Zardini, A. A., Marcolli, C., Krieger, U. K., and Peter, T.: Hygroscopic growth and water uptake kinetics of two-phase aerosol particles consisting of ammonium sulfate, adipic and humic acid mixtures, J. Aerosol Sci., 38, 157-171, https://doi.org/10.1016/j.jaerosci.2006.11.005, 2007.

Smith, J. N., Barsanti, K. C., Friedli, H. R., Ehn, M., Kulmala, M., Collins, D. R., Scheckman, J. H., Williams, B. J., and McMurry, P. H.: Observations of aminium salts in atmospheric nanoparticles and possible climatic implications, P. Natl. Acad. Sci. USA, 107, 6634-6639, https://doi.org/10.1073/pnas.0912127107, 2010.

Spinner, E.: Raman-spectral depolarisation ratios of ions in concentrated aqueous solution. The next-to-negligible effect of highly asymmetric ion surroundings on the symmetry properties of polarisability changes during vibrations of symmetric ions. Ammonium sulphate and tetramethylammonium bromide, Spectrochim. Acta, Part A, 59, 1441-1456, https://doi.org/10.1016/s1386-1425(02)00293-7, 2003.

Sullivan, R. C. and Prather, K. A.: Investigations of the diurnal cycle and mixing state of oxalic acid in individual particles in Asian aerosol outflow, Environ. Sci. Technol., 41, 8062-8069, https://doi.org/10.1021/es071134g, 2007.

Tang, I. N. and Munkelwitz, H. R.: Aerosol growth studies - III ammonium bisulfate aerosols in a moist atmosphere, J. Aerosol Sci., 8, 321-330, https://doi.org/10.1016/0021-8502(77)900192, 1977.

Tang, I. N. and Munkelwitz, H. R.: Water activities, densities, and refractive indices of aqueous sulfates and sodium nitrate droplets of atmospheric importance, J. Geophys. Res., 99, 18801-18808, https://doi.org/10.1029/94JD01345, 1994a.

Tang, I. N. and Munkelwitz, H. R.: Aerosol phase transformation and growth in the atmosphere, J. Appl. Meteorol., 33, 791-796, https://doi.org/10.1175/15200450(1994)033<0791:Aptagi>2.0.Co;2, 1994b. 
Treuel, L., Sandmann, A., and Zellner, R.: Spatial separation of individual substances in effloresced crystals of ternary ammonium sulphate/dicarboxylic acid/water aerosols, Chem. Phys. Chem., 12, 1109-1117, https://doi.org/10.1002/cphc.201000738, 2011.

Villepin, J. D. and Novak, A.: Vibrational spectra of and isotope effect in hydrogen bonded potassium hydrogen oxalate, Spectrosc. Lett., 4, 1-8, https://doi.org/10.1080/00387017108078634, 1971.

Von Schneidemesser, E., Monks, P. S., Allan, J. D., Bruhwiler, L., Forster, P., Fowler, D., Lauer, A., Morgan, W. T., Paasonen, P., Righi, M., Sindelarova, K., and Sutton, M. A.: Chemistry and the linkages between air quality and climate change, Chem. Rev., 115, 3856-3897, https://doi.org/10.1021/acs.chemrev.5b00089, 2015.

Wang, B. and Laskin, A.: Reactions between water-soluble organic acids and nitrates in atmospheric aerosols: Recycling of nitric acid and formation of organic salts, J. Geophys. Res., 119, 33353351, https://doi.org/10.1002/2013jd021169, 2014.

Wang, F., Zhang, Y. H., Zhao, L. J., Zhang, H., Cheng, H., and Shou, J. J.: Micro-Raman study on the conformation behavior of succinate in supersaturated sodium succinate aerosols, Phys. Chem. Chem. Phys., 10, 4154-4158, https://doi.org/10.1039/b719457a, 2008.

Wang, G. H., Kawamura, K., Cheng, C. L., Li, J. J., Cao, J. J., Zhang, R. J., Zhang, T., Liu, S. X., and Zhao, Z. Z.: Molecular distribution and stable carbon isotopic composition of dicarboxylic acids, ketocarboxylic acids, and $\alpha$-dicarbonyls in size-resolved atmospheric particles from Xi'an City, China, Environ. Sci. Technol., 46, 4783-4791, https://doi.org/10.1021/es204322c, 2012.
Wang, Y., Ma, J. B., Zhou, Q., Pang, S. F., and Zhang, Y. H.: Hygroscopicity of mixed glycerol/ $\mathrm{Mg}\left(\mathrm{NO}_{3}\right)_{2} /$ water droplets affected by the interaction between magnesium ions and glycerol molecules, J. Phys. Chem. B, 119, 5558-5566, https://doi.org/10.1021/acs.jpcb.5b00458, 2015.

Wise, M. E., Surratt, J. D., Curtis, D. B., Shilling, J. E., and Tolbert, M. A.: Hygroscopic growth of ammonium sulfate/dicarboxylic acids, J. Geophys. Res., 108, 4638, https://doi.org/10.1029/2003jd003775, 2003.

Yang, L. and Yu, L. E.: Measurements of oxalic acid, oxalates, malonic acid, and malonates in atmospheric particulates, Environ. Sci. Technol., 42, 9268-9275, https://doi.org/10.1021/es801820z, 2008.

Yeung, M. C., Lee, A. K. Y., and Chan, C. K.: Phase transition and hygroscopic properties of internally mixed ammonium sulfate and adipic acid (AS-AA) particles by optical microscopic imaging and Raman spectroscopy, Aerosol Sci. Technol., 43, 387399, https://doi.org/10.1080/02786820802672904, 2009.

Yli-Juuti, T., Zardini, A. A., Eriksson, A. C., Hansen, A. M. K., Pagels, J. H., Swietlicki, E., Svenningsson, B., Glasius, M., Worsnop, D. R., Riipinen, I., and Bilde, M.: Volatility of organic aerosol: evaporation of ammonium sulfate/succinic acid aqueous solution droplets, Environ. Sci. Technol., 47, 12123-12130, https://doi.org/10.1021/es401233c, 2013.

Zhou, Q., Pang, S. F., Wang, Y., Ma, J. B., and Zhang, Y. H.: Confocal Raman studies of the evolution of the physical state of mixed phthalic acid/ammonium sulfate aerosol droplets and the effect of substrates, J. Phys. Chem. B, 118, 6198-6205, https://doi.org/10.1021/jp5004598, 2014. 